\title{
Clodius Albinus und der Bürgerkrieg von 197
}

\author{
Mattbäus Heil
}

\section{Die Schlacht von Lyon und die Verfassung des Römischen Reiches}

150.000 Mann sollen es gewesen sein, die an einem Wintertag im Februar 197 n. Chr. bei Lyon gegeneinander kämpften. ${ }^{1}$ Es war eine der größten Schlachten der römischen Geschichte, aber alle Beteiligten waren römische Soldaten: Es herrschte Bürgerkrieg. Am Ende des Tages hatten Tausende ihr Leben oder ihre Gesundheit verloren, aber statt zweier rivalisierender Augusti gab es nur noch einen: nicht D. Clodius Albinus, sondern L. Septimius Severus, den Mann aus Africa. ${ }^{2}$

Man könnte die Schlacht als welthistorische Episode bagatellisieren oder sie mit dem Gemeinplatz abtun, der Streit der Großen werde immer auf dem Rücken der kleinen Leute ausgetragen. Aber das Römische Reich der Kaiserzeit wird uns meist als wohlgeordnetes System vorgestellt. So verdient es Interesse, wie es zu diesem Gemetzel kam, oder besser: warum es nicht verhindert wurde, obwohl angeblich niemand den Bürgerkrieg gewollt hat.

Hier berührt man die Frage nach der Verfassung des Reiches. Bekanntlich wurde darüber viel diskutiert, ohne daß man ein allseits gesichertes

1 Zahl bei Cass. Dio 75, 6, 1. Dies wäre gut die Hälfte aller Truppen unter römischem Befehl. Die Angabe scheint grundsätzlich plausibel, müssen doch bei einer Entscheidungsschlacht alle Reserven ins Gefecht geworfen werden. Die Größe der Schlachten des Severus wird auch angesprochen von Herod. 3, 7, 7. - Alle hier angeführten Daten betreffen die Zeit „n. Chr.“, so daß im Folgenden darauf verzichtet werden kann, dies jeweils ausdrücklich anzugeben.

2 Grundlegend zu allem, was Septimius Severus betrifft, ist nach wie vor A. R. Birley, The African Emperor. Septimius Severus, London 1988. Zu Datierungsfragen ist immer noch J. Hasebroek, Untersuchungen zur Geschichte des Kaisers Septimius Severus, Heidelberg 1921 von Belang, obwohl das Werk stark revisionsbedürftig ist. - Zu Clodius Albinus siehe PIR ${ }^{2}$ C 1186. 
Ergebnis erreicht hat. Theodor Mommsen ${ }^{3}$ hatte den Principat als Amt aufgefaßt und das Kaisertum damit als konstitutionelle Monarchie avant la lettre interpretiert. Dies zu widerlegen, hat sich längst erübrigt. Ronald Syme hatte skeptisch-nüchtern geschrieben: „The principate baffles definition."4 Aber seine Darstellung der augusteischen Zeit wurde für die folgenden Epochen wohl nicht so weitergedacht, wie sie es verdient hätte. Es ist immer wieder versucht worden, das Kaisertum als festen Typus, als ein Quasi-Amt zu beschreiben. In Fergus Millars berühmten Buch „The Emperor in the Roman World“ 5 wird der römische Kaiser unausgesprochen mit einem modernen Regierungschef verglichen und nach der Innenpolitik gefragt, die dieser römische prime minister betrieb. Freilich ließ sich keine kohärente Politik feststellen, und es existierte dafür auch nicht der nötige Behördenapparat. ${ }^{6}$

Wahrscheinlich sollte man auf mehreren Ebenen zugleich weiterdiskutieren. Zum einen müßte man klären, was genau man mit, Verfassung meint. Ich möchte im Folgenden darunter verbindliche Vorschriften verstehen, wie wesentliche politische Streitfragen zu lösen sind. Doch fragt sich, ob es eine so verstandene Verfassung im Kaiserreich überhaupt je gegeben hat. Zum zweiten wäre nach der Einheitlichkeit des Kaisertums zu fragen. In der Forschung wurde sie vielleicht allzu selbstverständlich vorausgesetzt und zu schnell gefolgert, daß man die Geschichte der einzelnen Kaiser zugunsten der allgemeinen Strukturen vernachlässigen dürfe. Doch scheint es eher so, daß der Inhalt des Kaisertums jeweils neu definiert werden konnte und mußte. ${ }^{7}$ Und nur weil dem so war, konnte das Kaisertum sich verändern, so daß sich der Principat des Augustus schließlich zur quasi-sakralen Monarchie der Spätantike wandelte.

Zum dritten wäre stets zu bedenken, daß der Kaiser nur theoretisch allmächtig war. Er war gut beraten, immer im Auge zu behalten, woher seine Macht kam und wieviel sie ihm wirklich zu tun erlaubte. Er war mit sozialen Kräften und Widerständen konfrontiert, die er nicht einfach beseitigen

3 Th. Mommsen, Römisches Staatsrecht, Bd. II 2, Leipzig 31887.

4 R. Syme, The Roman Revolution, Oxford 1939, 21952, 323.

5 London 1977.

6 Für die Außenpolitik stellt das Millar selbst heraus: Emperors, Frontiers and Foreign Relations 31 B.C. to A.D. 378, Britannia 13, 1982, 1-23; auch in: ders., Rome, the Greek World, and the East, Bd. 2: Government, Society and Culture in the Roman Empire, Chapel Hill - London 2004, 160-194. Vgl. auch M. Horster, Bauinschriften römischer Kaiser. Untersuchungen zu Inschriftenpraxis und Bautätigkeit in Städten des westlichen Imperium Romanum in der Zeit des Prinzipats (Historia. Einzelschriften 157), Stuttgart 2001, wo festgestellt wird, daß es keine kohärente kaiserliche Baupolitik gab.

7 Vgl. auch A. Winterling, Caligula. Eine Biographie, München 2003. 
konnte. Und die Machtfaktoren in der Gesellschaft konnten ihre eigene Vision vom Kaisertum besitzen. ${ }^{8}$ Eine offene Diskussion wurde aber nicht zugelassen. Allenfalls auf der Ebene der praktischen Politik ließ sich ein Ausgleich oder eine Entscheidung herbeiführen. Hier spielte es durchaus eine Rolle, wer der Kaiser war, welche Lage er vorfand und wie er mit ihr umging. ${ }^{\text {? }}$

Solange ein Konsens der maßgeblichen Kräfte bestand und weitertradiert wurde, funktionierte das Imperium Romanum der Kaiserzeit erstaunlich gut. Was aber, wenn nicht? Wenn so viel von den Menschen und den Umständen abhing, wie hier behauptet wurde, dann hülfe es wenig, nach einer allgemeinen Antwort zu suchen. Man muß den einzelnen Fall betrachten. Und damit können wir zur eingangs formulierten Frage zurückkehren, warum es zu dem Bürgerkrieg gekommen ist, der in der Schlacht von Lyon gipfelte.

\section{Die Nachfolgekrise von 193-197}

Septimius Severus und Clodius Albinus waren ursprünglich keine Rivalen, sondern Verbündete. So muß man zunächst in das Vierkaiserjahr 193 zurückblicken, in dem sie zueinanderfanden. Die Wirren nach dem Tod des Commodus sind zwar schon oft behandelt worden. ${ }^{10}$ Doch lohnt es sich zu verfolgen, wie und unter welchen Umständen ihre Allianz Gestalt annahm.

Eines der zentralen Probleme einer jeden Monarchie ist die Herrschaftsnachfolge. Das Vierkaiserjahr 193 illustriert vor allem eines: daß es hierfür im Imperium Romanum keine feste Regel gab. Der Kaiser Commodus wurde am 31. Dezember 192 von Personen aus seiner engsten Umgebung ermordet.

8 Die uns vorliegenden literarischen Quellen sind wohl nur bedingt repräsentativ für die Gesamtgesellschaft. Sie gewähren Einblicke vor allem in die Gedankenwelt der Senatsaristokratie und allenfalls der gebildeten Oberschicht. Ob z. B. die Soldaten und die plebs urbana genauso dachten, erscheint fraglich, und die wenigen, indirekten Hinweise sprechen eher dagegen. Die kleinen Leute waren anscheinend weniger an einem Staatslenker interessiert, der sich als der erste Bürger gab, sondern mehr an einem starken, jovialen Alleinherrscher, der als Patron der einfachen Menschen handelte und die Großen notfalls streng in die Schranken wies.

9 Die hier vorgetragenen Überlegungen berühren sich in einigen Punkten mit denen von E. Flaig (Den Kaiser herausfordern. Die Usurpationen im Römischen Reich, Frankfurt/Main 1992 und spätere Arbeiten), ohne deren recht artifiziellen Begriffsapparat und ihre Schlußfolgerungen zu übernehmen.

10 Siehe hierzu und zum Folgenden zusammenfassend Birley, Septimius Severus (wie Anm. 2). 
Er hinterließ weder einen Sohn noch einen designierten Nachfolger. Zwar präsentierten die Mörder schon am 1. Januar 193 einen neuen Herrscher: den alten Stadtpräfekten Helvius Pertinax. ${ }^{11}$ Doch er war offenkundig eine Verlegenheitslösung.

Der Senat träumte von einer idealisierten Antoninen-Monarchie, das heißt von der Herrschaft des (in ihren Begriffen) vornehmsten Senators. Pertinax versuchte, ihrem Wunschbild geradezu exemplarisch zu entsprechen und ist damit kläglich gescheitert. Gerade im Senat war er mit erheblichen Widerständen konfrontiert. ${ }^{12}$ Pertinax war ein Aufsteiger, dem nach traditionell-senatorischen Maßstäben nicht die Stellung an der Spitze gebührte. Und an seiner Herkunft konnte er nichts ändern.

Die Prätorianergarde wurde von Pertinax vernachlässigt. Dabei gab es die Tradition, daß die Garde den Kaiser machte. Doch existierte bei ihr kein geordnetes Verfahren der politischen Willensbildung - und dies durfte es beim Militär auch nicht geben. Einflußreiche Wortführer konnten die Gardesoldaten in Krisenfällen zu Gewaltstreichen aufstacheln: Das genügte, um Pertinax zu ermorden. Eine konsistente Politik ließ sich aber darauf nicht gründen.

Nach dem Tod des Pertinax hat Didius Iulianus bei der sogenannten Auktion des Kaisertums die Prätorianer mit dem Versprechen großer Geldgeschenke auf seine Seite gebracht und so die Herrschaft erobert. Doch außer den Begünstigten dürfte es niemandem eingeleuchtet haben, daß der Sinn des Kaisertums nur in der Bereicherung von ein paar tausend Soldaten bestehen sollte. Am Ende haben nicht einmal die Prätorianer ernsthaft für Didius Iulianus gekämpft.

Die Armeen in den Provinzen übertrafen an Zahl und Kampfkraft die Prätorianergarde um ein Vielfaches. Doch spielten sie gewöhnlich keine Rolle, wenn in Rom binnen Stunden eine Entscheidung fiel. Anfang 193 war aber für einige Monate vieles offen. Selbstverständlich waren auch die Provinzheere nicht auf eine eigene Willensbildung hin organisiert. Doch mit den senatorischen Kommandeuren gab es potentiell regimentsfähige Anführer. In der labilen Situation des Frühjahres 193 meldeten drei von ihnen ihre

11 Zu seiner Herkunft und Karriere vgl. PIR ${ }^{2} \mathrm{H} 73$.

12 Siehe die Verschwörung des Q. Sosius Falco, des consul ordinarius von 193 (PIR² P 655 mit Auflistung der Zeugnisse). Er entstammte einer hochadeligen Familie; bereits sein Vater und sein Großvater waren consules ordinarii gewesen (PIR P 612 bzw. 656). Pertinax hat es nicht gewagt, diesen Mann für seinen Hochverrat zu bestrafen. - Auch die Haltung des Claudius Pompeianus, des noch lebenden Schwiegersohns Marc Aurels, blieb undurchsichtig (PIR² C 973 mit Zeugnissen). 
Ansprüche an. Es waren die Kommandeure der größten Heere: Pescennius Niger, der Legat von Syrien, Septimius Severus, der Legat von Oberpannonien, und Clodius Albinus, der Legat von Britannien (siehe Karte 1). Schon damals dürfte klar gewesen sein, daß sie ihre Soldaten würden belohnen müssen, sobald sie mit ihrer Hilfe die Herrschaft errungen hatten.

Eine Kraft wurde noch nicht erwähnt, und sie wird auch oft übersehen: die öffentliche Meinung. Von den Protagonisten der nun einsetzenden Bürgerkriege wurde sie sehr ernst genommen, am meisten wohl von Septimius Severus. ${ }^{13}$ Selbstverständlich wurde der Bürgerkrieg vom Publikum verabscheut. So versuchten die Prätendenten zu zeigen, daß sie ihn zu vermeiden trachteten oder wenigstens im Interesse eines hohen Gutes handelten. Aber - und das scheint mir wichtig - es wurde nicht nur Propaganda betrieben, sondern die Rücksichtnahme auf die öffentliche Meinung beeinflußte auch die reale Politik. ${ }^{14}$

\section{Die Ursprünge der Idee der Machtteilung}

Pescennius Niger und Septimius Severus ließen sich im Frühjahr 193 nahezu gleichzeitig von ihren Truppen zum Kaiser ausrufen, ${ }^{15}$ und die jeweiligen Nachbarprovinzen schlossen sich an. Niger verfügte über eine gewisse

$13 \mathrm{Zu}$ seiner, Öffentlichkeitsarbeit' gehörte allem Anschein nach seine Autobiographie, die in den vorliegenden Quellen wiederholt erwähnt wird (Fragmente bei H. Peter, Historicorum Romanorum Reliquiae, Bd. 2, Leipzig 1906, 118-120, siehe bes. Herod. 2, 9, 4). Ferner berief sich Severus gegenüber dem Publikum in hohem $\mathrm{Maß}$ auf Orakel und auf die Astrologie, siehe dazu besonders Z. Rubin, Civil War Propaganda and Historiography (Collection Latomus 173), Brüssel 1980. Zur Berufung auf Orakel im Albinus-Krieg siehe auch G. Alföldy, Pannoniciani augures, in: ders.: Die Krise des Römischen Reiches. Geschichte, Geschichtsschreibung und Geschichtsbetrachtung. Ausgewählte Beiträge (HABES 5), Stuttgart 1989, 139-163 (zuerst 1960, hier mit Nachträgen). - Auch Cassius Dio hatte sich in seiner Jugend daran beteiligt, indem er ein Werk über die Vorzeichen und Träume verfaßte, die die Herrschaft des Severus ankündigten (und damit als vom Schicksal gewollt legitimierten). Ein Exemplar sandte er an Severus und erhielt von diesem ein freundliches Dankschreiben (Cass. Dio 72, 23, 1).

14 Wenn man diese Öffentlichkeit als Personen fassen will, so ist nicht nur an den Senat und die Soldaten zu denken, sondern vor allem an die lokalen Eliten, den Ritterstand und an die Gebildeten - immerhin einen Kreis von Zehntausenden von Personen. Ohne deren wohlwollende Duldung konnte kein Regime auf die Dauer bestehen.

15 Bei Severus kennt man das genaue Datum: den 9. April 193, siehe P. Dura 54 (das feriale Duranum). 
Popularität in Rom. ${ }^{16}$ Severus jedoch fand eine zündende Parole: die Rache für den ermordeten Kaiser Pertinax. So konnten er und seine Anhänger ihre Rebellion als eine höchst löbliche Tat darstellen. Severus selbst nahm den Namen ,Pertinax' an und hielt zeitlebens daran fest. Der Sieg gegen Didius Iulianus gelang rasch und leicht.

Noch während Severus in höchster Eile auf Rom marschierte, hatte er Verhandlungen mit Clodius Albinus angeknüpft: Er hatte Albinus brieflich den Caesar-Titel angeboten, ${ }^{17}$ es war zum Austausch von Botschaften gekommen, und noch vor dem Sieg über Didius Iulianus war eine Einigung gelungen. Deren Inhalt wird in den griechischen literarischen Quellen als ,Teilhaberschaft ${ }^{\prime}$ des Albinus an der Herrschaft des Severus umschrieben, ${ }^{18}$ wobei unklar bleibt, ob Severus und Albinus selbst diesen schillernden Begriff verwendet haben. Konkretes ist nur den unmittelbaren praktischen Folgen zu entnehmen: Septimius Severus blieb ,Augustus', während Albinus den Titel eines ,Caesar' erhielt. Ferner nahm Albinus den Namen ,Severus‘ an. Beide amtierten im Jahr 194 gemeinsam als consules ordinarii, und in Rom wurden Münzen auch im Namen des Albinus geprägt. ${ }^{19}$ Inwieweit darüber hinaus die Details der künftigen Zusammenarbeit abgesprochen wurden, muß offenbleiben. Die taktische Bedeutung des Bündnisses ist offensichtlich: Severus sicherte sich einen freien Rücken für den Krieg gegen Didius Iulianus und vor allem für die anstehende Auseinandersetzung mit Pescennius Niger. Albinus hingegen wurde Teilhaber an einem Kaisertum, ohne selbst dafür kämpfen zu müssen. Hätten sich Severus und Niger im Bürgerkrieg gegenseitig aufgerieben, wäre er zudem wohl der lachende Dritte gewesen.

Das Zweckbündnis implizierte aber den bemerkenswerten Gedanken, daß potentielle Rivalen sich zu einer gemeinsamen Herrschaft zusammenschlossen. Inspiriert wurde er offenkundig von der jüngeren Vergangenheit:

16 Cass. Dio 74, 13, 5; 74,15, 2; Herod. 2, 7, 3-5; HA Pesc. Niger 2, 2; 3, 1: Es gab in Rom im Circus eine Demonstration für ihn.

17 Cass. Dio 75, 15, 1-2; ganz ähnlich Herod. 2, 15, 3.

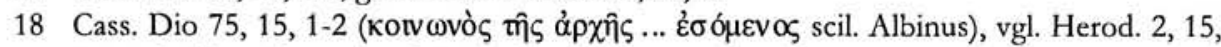

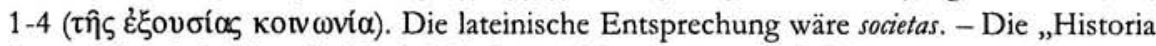
Augusta“" weicht hier ab: Nach HA Sev. 6,9 hat Severus lediglich erwogen, Albinus zu seinem Nachfolger zu ernennen (de Clodio Albino sibi substituendo cogitavit); nach HA Sev. 6, 11 wurde ein Heraclitus (PIR ${ }^{2} \mathrm{H} 88$ ) von Severus ad optinendas Britannias geschickt. Allerdings erscheint es so gut wie ausgeschlossen, daß der Emissär des Severus die Statthalterschaft an sich zu reißen suchte. Worum es tatsächlich ging, bleibt unklar; vielleicht liegt eine Verwechslung von Britannien mit Bithynien vor (vgl. HA Pesc. Niger 5, 2). Siehe auch A. R. Birley, The Fasti of Roman Britain, Oxford 1981, $295 \mathrm{f}$.

19 RIC IV 1 Clodius Alinus 1-12A; 50-63; vgl. auch Herod. 2, 15, 5. 
Bereits Hadrian hatte einen Caesar ernannt; ${ }^{20}$ auch Antoninus Pius kooptierte einen Caesar, den späteren Marc Aurel. Nach dem Tod des Pius regierten sogar zwei Augusti gemeinsam: Marc Aurel und Lucius Verus. Ferner wurde Commodus, der Sohn Marc Aurels, schon früh zum Caesar ernannt und einige Zeit nach dem Tod des Verus zum mitregierenden Augustus erhoben. Die Caesar-Ernennung bedeutete hier jeweils die Designation zum Nachfolger. Das gleiche ist bei Clodius Albinus vorauszusetzen. Die severische Propaganda spielte auch deutlich darauf an, zumal die Söhne des Severus damals erst vier und fünf Jahre alt waren. ${ }^{21}$ Allerdings war Albinus annähernd so alt wie Severus. ${ }^{22} \mathrm{Um}$ so mehr wurde die Offerte als ein Mittel dargestellt, um den Bürgerkrieg überflüssig zu machen. Mit dem AugustusRang des Severus und dem Caesar-Titel des Albinus war die Ungleichheit der Partner von Anfang an festgeschrieben. Das ist deshalb bemerkenswert, weil es zuvor auch die Herrschaft gleichberechtigter Augusti gegeben hat.

In der Antoninen-Zeit waren die Caesares und Augusti allerdings entweder zugleich Vater und Sohn oder Brüder. Allein schon deswegen durfte ein antoninischer Caesar fest mit der Nachfolge rechnen. Hingegen waren Severus und Albinus nicht persönlich aneinander gebunden - außer durch ihre Absprache. Beinahe gleichzeitig ist ein weiteres Angebot einer Samtherrschaft unterbreitet worden. Denn als Severus fast schon vor Rom stand und die Truppen des Didius Iulianus kampflos davonliefen, ließ dieser dem Severus durch einen Senatsbeschluß die Mitherrschaft antragen. ${ }^{23}$ Severus ging - selbstverständlich - nicht darauf ein. Didius Julianus wollte ganz offensichtlich nur seinen Kopf retten, und für Severus lagen in dem Angebot viele Nachteile, aber kein echter Vorteil. Schon kurz darauf fand sich Iulianus von allen Gefolgsleuten verlassen und wurde in vorauseilendem Gehorsam ermordet.

Severus trat in Rom eher als Eroberer denn als Befreier auf. Die Prätorianerkohorten wurden strafweise aufgelöst und durch ergebene pannonische Soldaten ersetzt. Die Garde spielte fortan keine politische Rolle mehr. Das Programm der ,Rache für Pertinax ' gipfelte in einer feierlichen Scheinbestat-

20 L. Aelius Caesar (PIR² C 605); vgl. auch A. R. Birley, Hadrian. The Restless Emperor, London 1997, 289-294.

21 Siehe Herod. 2, 15, 4 (Brief des Severus an Albinus); HA Pesc. Niger 4, 7 (mit Berufung auf die Autobiographie des Severus); HA Clod. Alb. 3, 4 (mit Berufung auf Marius Maximus); 10, 3. Severus war damals knapp 50. Das ungefähre Alter des Albinus kann man aus seiner Karriere erschließen. HA Clod. Alb. 4, 5 ist wertlos.

22 Vgl. auch HA Pesc. Niger 7, 1 (mit Berufung auf die Autobiographie des Severus).

23 Cass. Dio 73, 17, 2; Herod. 2, 12, 3-5; HA Did. Iul. 6, 5-9; HA Sev. 5, 7. 
tung des ermordeten Kaisers und seiner Divinisierung. ${ }^{24}$ Dem Senat zollte Severus Respekt, ließ aber erkennen, daß er das Heft in der Hand behalten wollte. Die Senatoren faßten dies als feindselig auf. Vermutlich hat Severus seine Lehre aus dem Scheitern des Pertinax gezogen. Denn er war - wie Pertinax - ein Emporkömmling und hatte nicht einmal eine glänzende Karriere absolviert. Nüchtern betrachtet, hatte er nie eine Chance, vom Senat jemals als dessen natürliches Oberhaupt respektiert zu werden. Der latente Zwist mit dem Senat bedeutete aber auch, daß seine Herrschaft von Anfang an mit einer schweren Hypothek belastet war.

Solange sich Severus in Rom aufhielt, hat er die Kaiserproklamation des Pescennius Niger verheimlicht. Schon nach 30 Tagen $^{25}$ brach er ohne Erklärung wieder auf. Offenkundig wollte er nicht zugeben müssen, daß er in einen Bürgerkrieg zog. Den Kämpfen gegen Niger ging offenbar ein kurzer, heftiger Propagandakrieg voran. Allem Anschein nach hat Severus auch ihm den Caesar-Titel angeboten. ${ }^{26}$ Severus wußte es ferner so einzurichten, daß die offenen Kämpfe von Aemilianus ${ }^{27}$ begonnen wurden, dem wichtigsten Parteigänger des Niger. Und selbst danach stellte er Niger noch ein sicheres Exil in Aussicht, forderte aber die Preisgabe des Aemilianus, der hier als Sündenbock für den Bürgerkrieg diente. ${ }^{28}$ Niger lehnte immer $a b$, hat aber möglicherweise seinerseits dem Severus - vergeblich - die Mitherrschaft angeboten. ${ }^{29}$

Der Konflikt selbst wurde militärisch entschieden. Severus erreichte einen schnellen und vollständigen Sieg. Bei Kyzikos und Issos gewannen seine Unterführer die entscheidenden Schlachten. Pescennius Niger geriet in Gefangenschaft und wurde getötet, ebenso Aemilianus; ihre Anhänger wurden bestraft. Bis Mitte 194 hatte Septimius Severus den ganzen römischen Osten unter seiner Kontrolle.

24 Cass. Dio 74, 4, 1-5; 7; HA Pert. 15, 1; HA Sev. 7, 8. Cassius Dio hat den Staatsakt als Augenzeuge miterlebt.

25 HA Sev. 8, 8; Herod. 2, 14, 5.

26 HA Pesc. Niger 4, 7; HA Clod. Alb. 3, 4. Die Angaben scheinen auf zeitgenössische Quellen aus dem Lager des Severus zurückzugehen, s. oben Anm. 21.

27 Asellius Aemilianus (PIR ${ }^{2}$ A 1211). Er war ein Verwandter des Clodius Albinus (Cass. Dio $74,6,2)$.

28 HA Sev. 8, 15; vgl. HA Pesc. Niger 4, 5; 5, 8.

29 Nach HA Sev. 8, 14 rief Niger den Severus ad participatum, was Severus aber ablehnte. Dieselbe Notiz steht auch in HA Pesc. Niger 5, 6. 


\section{Der Weg in den Krieg zwischen Albinus und Severus}

Der Gedanke, den Krieg durch die Teilung der Herrschaft zu vermeiden, war im Jahr 193 also allenthalben im Schwange, wurde jedoch meist für propagandistische Zwecke benutzt. Nur Albinus und Severus ließen sich tatsächlich auf den Versuch einer gemeinsamen Herrschaft ein. Es stellte sich nun aber die Frage, ob ihre eilig im Krieg ausgehandelte Übereinkunft mehr sein würde als ein taktisches Bündnis auf Zeit.

In den literarischen Quellen wird dies klar verneint. Vielmehr wird behauptet, Severus habe sofort gezielt die Auseinandersetzung mit Albinus gesucht. Herodian und die „Historia Augusta“ behaupten, Severus habe Boten mit Briefen an Albinus geschickt, die ihn bei einem persönlichen Gespräch ermorden sollten. Doch habe Albinus die Gefahr rechtzeitig erkannt, und unter der Folter hätten die Mordboten alles gestanden. ${ }^{30} \mathrm{Ob}$ das stimmt, scheint zweifelhaft. Herodian unterschlägt im gleichen Zusammenhang den ersten Orientkrieg des Severus, ${ }^{31}$ und ihm war auch sonst eine eingängige Dramaturgie weit wichtiger als die spröden Tatsachen. Die „Historia Augusta“ bietet Material sehr unterschiedlicher Qualität. Der Senator Cassius Dio jedoch weiß nichts von dem angeblichen Mordanschlag. Er schreibt einfach, Severus habe dem Albinus den Caesar-Titel nicht mehr zugestanden, während dieser nach der höchsten Kaiserwürde strebte. ${ }^{32}$ Allerdings war im Grunde auch er gegen Severus eingestellt.

30 Herod. 3, 5, 2-8 (Anlaß sei gewesen, daß sich Albinus mit seinem Caesar-Titel bereits wie

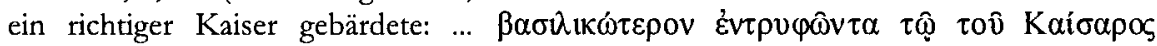
óvó $\mu \alpha \tau$ ); HA Clod. Alb. 7, 2ff. - In HA Clod. Alb. 3, 5 wird der Neid des Severus auf die Beliebtheit des Albinus und die Agitation Iulia Domnas als Motiv angegeben. - Die absurde Behauptung in HA Clod. Alb. 1, 1; 14, 2; 14, 6, Albinus habe Didius Iulianus zur Ermordung des Pertinax angestiftet, ist vielleicht eine Retourkutsche der severischen Propaganda.

31 Herod 3, 5, 1. - Zur Darstellung Herodians vgl. auch M. Zimmermann, Kaiser und Ereignis. Studien zum Geschichtswerk Herodians (Vestigia. Beiträge zur Alten Geschichte 52), München 1999, bes. 189-194.

32 Cass. Dio 75, 4, 1. Allerdings handelt es sich nicht um den Originaltext, sondern um ein späteres Exzerpt. - In HA Sev. 10, 1 wird der Beginn des Bürgerkriegs ganz knapp und ähnlich wie bei Dio geschildert. - Aus diesen wie aus den oben in Anm. 30 zitierten Stellen gewinnt man leicht den Eindruck, der Krieg sei im wesentlichen aus den Charakteren der Hauptpersonen zu erklären. Alle diese literarischen Quellen folgen jedoch einer stark personalisierten Geschichtsdeutung. 
Die moderne Forschung sieht ebenfalls in Severus den Urheber des Krieges. ${ }^{33}$ Dort kommen noch chronologische Argumente hinzu. Es wird angenommen, daß sich Septimius Severus ab 195 nicht nur als divi Marci filius (als Sohn des vergöttlichten Marc Aurel) bezeichnen ließ, sonde rn daß er im gleichen Jahr seiner Frau Iulia Domna den Titel mater castrorum verliehen habe und seinen Sohn Bassianus - den späteren Caracalla - unter dem Namen M. Aurelius Antoninus zum Caesar erhoben habe. Dies wäre in der Tat eine Kampfansage an Albinus gewesen. Entsprechend wird gelegentlich auch behauptet, Albinus sei schon Ende 195 zum hostis (zum Staatsfeind) erklärt worden. ${ }^{34}$

Wäre dem so, hätte Severus aber den fundamentalen strategischen Fehler begangen, Albinus zum Krieg herauszufordern, während er selbst und sein Heer noch im Orient gebunden waren. Und Albinus hätte so einfältig sein müssen, über ein Jahr einfach zuzuwarten, obwohl er nichts mehr zu verlieren hatte. In den literarischen Quellen findet sich nichts von all dem, obwohl es bestens zu ihrer antiseverischen Tendenz gepaßt hätte. Ein genauerer Blick auf die Zeugnisse legt überdies nahe, daß die CaesarErhebung Caracallas und ebenso der neue Titel Iulia Domnas erst in das Frühjahr 196 gehören. ${ }^{35}$ Und der „Historia Augusta“ zufolge wurde Albinus erst nach dem Ausbruch der offenen Kämpfe zum bostis erklärt. ${ }^{36}$ Auch alle sonstigen Indizien sprechen gegen eine bostis-Erklärung vor $196 .{ }^{37}$

33 Siehe zusammenfassend Birley, Septimius Severus (wie Anm. 2) 115-120, bes. 117. Etwas ausgewogener ist die Ansicht, sowohl Severus als auch Albinus hätten schlichtweg die Alleinherrschaft an sich reißen wollen, so Zimmermann, Kaiser (wie Anm. 31), bes. 187 und 191-193. Er folgt darin einer in den literarischen Quellen angelegten Meinung, die die Dinge aber sichtlich simplifiziert (vgl. auch Anm. 32).

34 Birley, Septimius Severus (wie Anm. 2) 120; D. Kienast, Römische Kaisertabelle. Grundzüge einer römischen Kaiserchronologie, Darmstadt 21996, 161 (mit Verweis auf Cass. Dio 75, 4, 2-6).

35 Siehe hierzu unten die Anhänge.

36 HA Clod. Alb. 9, 1 (im Kontext nachweislich zutreffender Informationen).

37 Für eine Datierung auf 195 wurde Cass. Dio 75, 4, 2-6 angeführt (s. oben Anm. 34). Der Autor berichtet dort, daß das Volk von Rom an den Saturnalien im Circus spontan für den Frieden demonstriert hat. Die Episode wird meist - und zweifellos zurecht - auf Dezember 195 datiert (anders beispielsweise F. Millar, A Study of Cassius Dio, Oxford 1964, 16; 141). Jedoch spricht nichts für einen Zusammenhang mit einer bostis-Erklärung, im Gegenteil: Dio schildert die Friedensdemonstration als eine Art Omen, als eine göttlich inspirierte Ahnung, die sich später bewahrheiten sollte. Dies setzt geradezu voraus, daß Albinus damals noch nicht zum bostis erklärt worden war. Denn sonst hätte es keiner prophetischen Gabe bedurft, um den Krieg vorherzusehen. 
Die Datierungsfragen sind hier mehr als bloße Quisquilien. Aus der revidierten Chronologie ergibt sich, daß Severus nach dem Ende des Pescennius Niger nicht sofort den Krieg gegen Clodius Albinus vom Zaun gebrochen hat. Vielmehr war der Weg in den neuen Bürgerkrieg bemerkenswert lang. Es lohnt sich, die Stationen durchzugehen.

Bei Albinus besitzt man keine festen Daten; man weiß nur, was er überhaupt tat: Zwischen Mitte 194 und Ende 196 hat er seine Provinz Britannien verlassen, ist nach Gallien übergesetzt und hat dort ohne Absprache mit Severus den Augustus-Titel angenommen. ${ }^{38}$ Er besetzte unter anderem Lyon und ließ dort Münzen prägen, die ihn als Augustus zeigen. ${ }^{39}$ Das Prägevolumen ist so groß, daß er die Münzstätte für längere Zeit unter seiner Kontrolle gehabt haben muß. Doch hat er den Beinamen ,Severus' sehr lange beibehalten. Es gibt nur eine einzige Inschrift, in der er fehlt, ${ }^{40}$ und diese stammt wohl erst aus der allerletzten Zeit vor seinem Untergang.

Auf sichererem Boden stehen wir bei Septimius Severus. Hier ist zunächst und vor allem festzuhalten, daß er nach dem Sieg über Pescennius Niger einen Krieg gegen die Parther und ihre Verbündeten im Orient führte. Dieser dauerte das ganze Jahr 195 über noch an. ${ }^{41} \mathrm{Ab}$ der ersten Hälfte dieses Jahres führte Severus die Siegerbeinamen Partbicus Arabicus und Partbicus Adiabenicus. ${ }^{42}$ Er beanspruchte also Teilerfolge, aber noch nicht den vollkommenen Parthersieg. Clodius Albinus erhielt an dem Titel keinen Anteil.

Ferner erscheint Severus ab der ersten Hälfte dieses Jahres auf Münzen und Inschriften als divi Marci filius (als Sohn Marc Aurels), öfters auch als Pius, was äquivalent gewesen zu sein scheint. ${ }^{43}$ Bei dieser merkwürdigen Selbstadoption sollte man bedenken, daß sein Regime inzwischen neue Rechtfertigungsstrategien benötigte. Denn das Programm der ,Rache für Pertinax war

38 Vgl. auch HA Sev. 10, 1: ... bellum civile Clodi Albini nuntiatum est, qui rebellavit in Gallia; HA Pesc. Niger 2, 1 (mit falscher zeitlicher Einordnung).

39 RIC IV 1 Clodius Albinus 13-49; 64.

40 W. Spickermann, Weihung zum Heile des Clodius Albinus, Laverna 7, 1996, 92-102 = AE 2000, 1848.

41 Siehe H. Halfmann, Itinera principum. Geschichte und Typologie der Kaiserreisen im Römischen Reich (HABES 2), Stuttgart 1986, 216f.; Kienast, Kaisertabelle (wie Anm. 34), 156.

42 RIC IV 1 Severus Nr. 41 und 55 (mit imp. IV), Nr. 58, 62, 690, 696 (mit imp. V); CIL VIII 306 = ILS 417; CIL X 7272; AE 1984, 373; P. Fam. Tebt. 47 (vom 14. August 195), P. Oxy. 3167 (vom September 195).

43 Divi Marci filius: RIC IV 1 Severus Nr. 686; CIL VIII 24004 - Pius: AE 1984, 373; IGR I $1290=$ SB 8392 (Juli/August 195), P. Fam. Tebt. 47 (vom 14. August 195); BGU 199. 
erfüllt, und der ,Rebell' Niger war besiegt. Der erfolgreiche Kampf gegen äußere Feinde gehörte stets zum Kern des Kaisertums. Ferner berief sich Severus vielfach auf Orakel und auf die Astrologie, d. h. er behauptete, das allmächtige Schicksal selbst habe ihn zum Kaiser ausersehen. ${ }^{44}$ Aber das ungeheuere legitimatorische Potential der Antoninen-Monarchie stand ungenutzt im Raum, und die Distanzierung von Commodus verlor mit dem wachsenden Zeitabstand immer mehr an Bedeutung. So lag es für Severus nahe, hier anzuknüpfen und das wichtige Thema nicht unbesetzt zu lassen. Ob die Verwandtschaftsfiktion im Reich buchstabengetreu geglaubt wurde, darf man bezweifeln. Man konnte sie vielleicht auch als das dezidierte Versprechen auffassen, daß alles wieder so werden sollte wie in der guten alten Zeit.

Clodius Albinus wurde in die fiktive Verwandtschaft nicht miteinbezogen, allerdings vorerst auch niemand anderer. Severus kehrte hervor, daß er der legitime Herrscher war - er allein. Clodius Albinus konnte darin eine Zurücksetzung und eine Provokation sehen, aber er hätte sich auch eine harmlosere Deutung zu eigen machen können. Eine unmißverständliche Kriegserklärung war dies jedenfalls nicht.

Am Ende des Jahres demonstrierte das Volk von Rom im Circus spontan für den Frieden. ${ }^{45}$ Offenbar zeichnete sich allmählich die Möglichkeit eines Bürgerkrieges ab. Anfang 196 brach Severus den Orientkrieg ab und kehrte in den Westen zurück. Das war allem Anschein nach eine grundsätzliche Änderung seiner Pläne. ${ }^{46}$ So liegt es überaus nahe, daß Albinus gegen Ende 195 etwas getan hatte, das Septimius Severus als unerträglich auffaßte. Man könnte vermuten, daß er z. B. Britannien verlassen hatte und nach Gallien übergesetzt war, womit er nach Meinung des Severus seine Befugnisse weit überschritt.

Möglicherweise hat sich Albinus ab irgendeinem Zeitpunkt seinerseits auf die Antoninen berufen: ${ }^{47}$ In der „Historia Augusta“ findet sich die seltsame Nachricht, Commodus habe Albinus zu seinem Nachfolger designiert, dieser habe aber von seinem Nachfolgerecht zunächst keinen Gebrauch gemacht. ${ }^{48}$ Vielleicht haben seine Propagandisten derartige Gerüchte ausgestreut. Sie hätten Albinus eine Legitimation verschafft, die nicht von Severus abhing.

44 Siehe dazu besonders Rubin, Propaganda (wie Anm. 13).

45 Cass. Dio 75, 4, 2-6; siehe oben Anm. 34 und 37.

46 Vgl. auch Cass. Dio $75,4,1$.

$47 \mathrm{Ob}$ Albinus damit auf Severus reagierte oder sogar als erster mit dem Rückbezug auf die Antoninen begann, läßt sich gegenwärtig nicht sagen.

48 HA Sept. Sev. 6, 9; HA Clod. Alb. 2, 1 ff; 3, 1. 3; 6, 3-5; 13, 4-9. 
Irgendwann wurde dann auch die Erzählung vom angeblichen Mordplan des Severus in Umlauf gesetzt, die zeigen sollte, daß Albinus nicht der Unruhestifter war, sondern das unschuldige Opfer.

Im April 196 verlieh Severus dann seiner Gattin den Titel mater castrorum. Es war dies der Titel, den Faustina II., die Gattin Marc Aurels, getragen hatte. ${ }^{49}$ Und wohl im Frühjahr des gleichen Jahres erhob er seinen ältesten Sohn zum Caesar und benannte ihn um; er hieß fortan M. Aurelius Antoninus. ${ }^{50}$ Ferner ließ sich Septimius Severus ab etwa der ersten Hälfte des Jahres als divi Commodi frater bezeichnen. ${ }^{51}$ Der Rückbezug auf die Antoninen wurde also sehr stark forciert, und jetzt schloß Severus ausdrücklich seine eigene Familie ein, nicht aber seinen Caesar Clodius Albinus. Der Caesar-Titel Caracallas bedeutete die faktische Aufkündigung der Samtherrschaft mit Albinus. Denn dieser durfte sich von da ab keinerlei Hoffnung mehr machen, jemals mit Billigung des Severus die Herrschaft über das Reich erben zu können.

Überraschenderweise wurde Caracalla in Viminacium an der Donau zum Caesar ernannt, und überraschenderweise geschah dies auf der Durchreise, $d$. h. auf dem Rückweg aus dem Orientkrieg. ${ }^{52}$ Das macht den Eindruck einer halb improvisierten Aktion. Anzumerken ist ferner, daß Caracalla damals erst acht Jahre alt war, ${ }^{53}$ daß er also seinen Rang noch lange nicht persönlich ausfüllen konnte. ${ }^{54}$ All das legt die Vermutung nahe, daß der Staatsakt von Viminacium die Reaktion auf eine weitere, provozierende Tat des Albinus gewesen ist. Möglicherweise hatte sich dieser inzwischen eigenmächtig zum Augustus ernannt. Und möglicherweise sollten die neuen Titel der SevererFamilie vor allem eines deutlich machen: den entschiedenen Widerspruch.

49 Zum Datum siehe unten Anhang 1.

50 HA Sev. 10, 3f,; zum Datum siehe unten Anhang 2.

51 CIL VIII 1333. $754=23107.12401 .23819 .25500$; CIL XIV 113-114 (mit Addenda S. 613); ILAfr 613 = IAM II 387. - Die Inschrift CIL VIII 9317, die angeblich von 195 stammt, ist nur durch eine schlechte Abschrift bekannt und heute verloren.

52 HA Sev. 10, 3; Näheres unten bei Anm. 94.

53 Geboren war er am 4. 2. 188. Das Tagesdatum ist aus P. Dura 54 bekannt, das Jahr errechnet sich aus Cass. Dio 78, 5, 4f. und 78, 6, 5. - Nach HA Sev. 16, 3 und HA Diad. 6,8 wäre er bereits 186 geboren. Das scheint aber nicht zuzutreffen.

54 Severus hat dabei die Option verworfen, seinen eigenen, echten Bruder P. Septimius Geta als dynastische Reserve heranzuziehen. Möglicherweise traute er Getas Loyalität und Fähigkeit nicht genügend oder wollte vermeiden, daß es später zwischen dem Bruder und dem Sohn zum Streit kam. In jedem Fall hätte die Einbeziehung Getas die Botschaft verunklärt, die von dem Staatsakt von Viminacium ausging. 
Clodius Albinus hingegen hat den Severus-Beinamen zunächst nicht abgelegt. Ferner hat er offensichtlich bewußt darauf verzichtet, in aller Eile auf Rom zu marschieren, obwohl Severus noch weit entfernt war. Damit hätte er sich zwar einen militärischen Vorteil verschafft, doch zugleich auch den Eindruck vermittelt, ohne Not den Bürgerkrieg zu beginnen. Allem Anschein nach hat Albinus die Wahrung seines öffentlichen Ansehens für wichtiger gehalten als den kurzfristigen militärischen Vorteil.

So konnte dann Septimius Severus etwa im Sommer 196 in Rom einziehen. Auf einen Triumph verzichtete er ebenso wie auf den Siegernamen Partbicus. 55 Mit der Zurückhaltung demonstrierte er, daß er den Krieg als noch nicht beendet betrachtete. Oder anders gesagt: Septimius Severus ließ die Welt wissen, daß Clodius Albinus den Kampf gegen die äußeren Feinde der res publica Romana massiv behindert habe.

Severus ließ ferner die Alpenpässe besetzen. ${ }^{56}$ Wohl gegen Ende 196 fand dann ein erstes Gefecht statt, das Albinus gegen einen Unterführer des Severus gewann. ${ }^{57}$ Und wohl erst danach ließ Severus den Caesar Albinus zum bostis, zum Staatsfeind erklären, nämlich als er nachweislich Bürgerblut vergossen hatte. ${ }^{58}$

\section{Worum ging es?}

Es sind also mindestens anderthalb Jahre voll höchster Spannung vergangen, bevor Severus und Albinus wirklich die Waffen gegeneinander kehrten. Selbst wenn man über den einen oder anderen Punkt der hier vorgestellten Chronologie noch diskutieren kann, scheint das Prinzipielle klar: Es kam zu einer schrittweisen Eskalation; Aktion und Reaktion schaukelten sich gegenseitig so weit auf, bis keine friedliche Lösung mehr möglich war. Damit

55 HA Sev. 9, 10-11, eine Notiz, die vielleicht auf zeitgenössische Pamphletistik zurückgeht. Denn daß Severus aus Furcht vor den Parthern den Parthicus-Titel abgelehnt habe, ist sicher eine übelwollende Unterstellung seiner Feinde.

56 Herod. 3, 6, 10.

57 Cass. Dio 75, 6, 2 (Sieg über Virius Lupus, vgl. HA Sev. 10, 7; HA Clod. Alb. 9, 1; zur Stellung des Lupus vgl. W. Eck, Die Statthalter der germanischen Provinzen vom 1.-3. Jahrhundert [Epigraphische Studien 14] Köln - Bonn 1985, 188f.). In die gleiche Zeit werden die Aktionen des Freischärlers Numerianus (PIR² N 198) gehören. Severus verdeutlichte, daß er diesen nicht beauftragt hatte.

58 So ausdrücklich HA Clod. Alb. 9, 1 (vgl. oben Anm. 36). - Auch der neue Bürgerkrieg ging mit einem heftigen Propagandakrieg einher, in dem man vor persönlichen Verunglimpfungen nicht zurückschreckte, vgl. HA Clod. Alb. 10, 1f.; 11, 4. 
ging ein Propagandakrieg einher, in dem jede Seite der anderen die Schuld zuzuschieben suchte. Hier könnte man die Frage stellen, ob die Eskalation zu verhindern gewesen wäre. Oder anders: Beruhte der Krieg letztlich nur auf wechselseitigen Überreaktionen? Dies wäre aber wohl zu naiv gedacht. Severus und Albinus traten mit deutlich verschiedenen Konzepten von Kaiserherrschaft an die Öffentlichkeit, die einander letztlich ausschlossen.

Severus legte größten Wert darauf, der oberste Herr des Reiches zu sein und zu bleiben. Darüber hat er nie mit sich reden lassen. Einen rangniedrigeren Teilhaber hätte er wohl akzeptiert, wenn dieser sich unterordnete. Klar scheint, daß er 194/195 zunächst keine Anstalten machte, um seinen Bündnispartner rasch wieder loszuwerden. Albinus hingegen forderte in der Öffentlichkeit die volle Gleichberechtigung mit Severus - nicht weniger, aber auch nicht mehr. Er wollte diesen nicht beseitigen, aber er wollte die gemeinsame Herrschaft nach dem Prinzip völliger Parität gestaltet wissen.

Es kann gut sein, daß beide Seiten geheime Hintergedanken verfolgten. Aber für den Erfolg im Ringen um die öffentliche Zustimmung zählte zunächst nur, was öffentlich vorgebracht wurde. Hier sprach der Augenschein gegen Clodius Albinus: Er hatte sich 193 mit dem Caesar-Rang begnügt und stellte nun zusätzliche Forderungen. Aber man muß ihm zubilligen, daß er unter einem Caesar möglicherweise etwas anderes verstanden hatte als Severus. Er betrachtete sich anscheinend als vollwertigen Mitherrscher. Der Caesar hätte demnach nur in der öffentlichen Ehre hinter dem Augustus zurückgestanden. Severus sah hingegen in einem Caesar offensichtlich nur den designierten Nachfolger, weiter nichts. Trifft das zu, dann wollte Albinus mit seinen Nachforderungen nur eine Klarstellung erreichen, während Severus darin eine Rebellion sah.

Wenn dies zutrifft, waren Severus' Vorstellungen eher durch die Tradition gedeckt als die des Albinus. Und die Alleinherrschaft eines einzigen Augustus war eine in sich stimmige Konstruktion, während es unklar blieb, wie zwei nahezu gleichberechtigte Herrscher nebeneinander regieren sollten, die weder verwandt noch sonst fest aneinander gebunden waren. ${ }^{59}$ Aber man kann deswegen nicht sagen, daß die Konzeption des Albinus falsch und unzulässig gewesen sei. In der römischen Welt der Kaiserzeit existierte keine Instanz, die dies hätte autoritativ beurteilen können; es gab kein festes, geordnetes Schlichtungsverfahren, dem sich auch ein Caesar und ein Augustus hätten unterwerfen müssen. So konnte der Konflikt am Ende nur

59 Immerhin war dies nicht unmöglich, wie später Diocletian und Maximian bewiesen. Allerdings verdankte Maximian seine Stellung ausschließlich seinem Kollegen, dem er sich offensichtlich stets verpflich tet fühlte. 
durch den freiwilligen Verzicht einer Seite oder eben mit Gewalt bereinigt werden.

Der Senat hat hier nichts zu einer Lösung beige tragen, sondern den Streit noch verschärft. Denn ein wesentlicher Teil der (vornehmen) Senatoren nahm Kontakt mit Albinus auf und sympathisierte offen mit ihm. Allem Anschein nach hofften sie, den ungeliebten Severus mit Hilfe des Albinus wieder loszuwerden. Für Severus bedeutete dies eine zusätzliche, existentielle Herausforderung.

\section{Der Krieg und die Folgen}

Doch zurück zu den Ereignissen: ${ }^{60}$ Der Kriegsplan des Albinus war recht durchsichtig. Er stand in der Region von Lyon und wartete offenkundig, bis im Frühjahr 197 die Alpenpässe schneefrei wurden, um dann von Südfrankreich her nach Oberitalien einzudringen (siehe Karte 2). ${ }^{61}$ Die Partei des Severus agierte wesentlich einfallsreicher. Dabei kam ihr zustatten, daß sie Raetien kontrollierte und daß Albinus nicht alle Gebiete des gallischgermanischen Raums hatte in seine Gewalt bringen können: Trier wurde von dessen Truppen vergeblich belagert und von der Mainzer Legion (legio XXII Primigenia) verteidigt. ${ }^{62}$ Severus und seine Heerführer konzentrierten ihre Hauptmacht daher nicht - wie zu erwarten - in Oberitalien, sondern auf dem scheinbaren Nebenkriegsschauplatz in Raetien und Obergermanien (siehe Karte 3). Und bereits im Winter 196/197 stießen sie von dort aus über Burgund nach Süden vor, wobei ihnen vielleicht ein milder Winter zu Hilfe kam. Albinus und seine Armee wurden offenbar vollkommen überrascht und gerieten unversehens in eine äußerst schwierige Lage. Für ihre eigenen Offensivpläne war die Jahreszeit noch zu früh, und ein Rückzug hätte soweit überhaupt durchführbar - die faktische Aufgabe Galliens bedeutet und wohl den Zusammenbruch des Regimes nach sich gezogen. So mußte sich Albinus zu einer Entscheidungsschlacht stellen, in der ihm nur ein vollständiger Sieg geholfen hätte.

60 Zum Kriegsverlauf siehe Birley, Septimius Severus (wie Anm. 2), 121-26, wo auch die Quellenbelege angeführt sind.

61 Sein Feldzug wäre dann nach dem gleichen Drehbuch verlaufen wie der des Vitellius von 69 - oder wie später der Constantins von 312 oder der Napoleons von 1796.

62 CIL XIII 6800 (aus Mainz, 197 nach dem Albinus-Krieg gesetzt); siehe Birley, Septimius Severus (wie Anm. 2), 122. 
Die Schlacht fand am 19. Februar 197 knapp nördlich von Lyon statt. Albinus kam einem Erfolg sehr nahe. Denn Septimius Severus nahm hier erstmals persönlich an einer Schlacht teil. Sein Flügel geriet in höchste Bedrängnis und wurde zurückgeworfen. ${ }^{63}$ Severus selbst verlor sein Pferd und mußte fliehen - und dabei alle seine kaiserlichen Rangabzeichen wegwerfen, um sich unkenntlich zu machen. Einer seiner Unterführer namens Laetus konnte jedoch mit einer Kavallerieattacke die Truppen des Albinus zurückwerfen. ${ }^{64}$ Die Schlacht endete mit einem vollständigen Sieg des Severus.

Albinus beging Selbstmord oder wurde getötet. Severus erbeutete unter anderem dessen Korrespondenz und ersah aus ihr das ganze Ausmaß der Kollusion führender Senatoren mit seinem Feind. Marc Aurel soll die Korrespondenz des Rebellen Avidius Cassius ungelesen verbrannt haben, als sie ihm in die Hände fiel. ${ }^{65}$ Septimius Severus dachte nicht daran, in gleicher Weise Milde walten zu lassen - sei es aus Zorn, oder sei es, weil er nicht glaubte, daß die Senatoren ihm die Milde danken würden.

Nach seiner Rückkehr nach Rom hielt er ein Strafgericht über die Anhänger des Albinus - oder aus seiner Sicht über die Kollaborateure mit dem Landesfeind. In den literarischen Quellen wird die Zahl der Hinrichtungen deutlich übertrieben ${ }^{66}$ - in der offenkundigen Absicht, Severus als besonders grausam erscheinen zu lassen. ${ }^{67}$ Ferner wurde Caracalla zum imperator destinatus erhoben ${ }^{68}$ - ein ad hoc erfundener Titel, der eine Zwischenstufe

63 Siehe Cass. Dio 75, 6, 6f.; Herod. 3, 7, 3; HA Sev. 11, 2 vgl. 18, 9; Vict. Caes. 20, 25. Die militärischen Details sind nicht recht klar; anscheinend war Severus in eine von Albinus vorbereitete Falle gestolpert.

64 Die Krise hatte später aber noch ein Nachspiel: Laetus (PIR I 373 ) brüstete sich sehr damit, daß Severus ihm den Sieg verdankte. Doch wurde ihm vorgeworfen, absichtlich gezögert zu haben, um am Ende selbst Kaiser zu werden, und schließlich wurde er hingerichtet (Cass. Dio 75, 6, 8; Herod. 3, 7, 3f;; ob er mit einem anderen Kommandeur namens Laetus - PIR ${ }^{2}$ L 69 - identisch war, bleibt unklar). Der Vorwurf gegen Laetus erscheint unplausibel, aber die tatsächlichen Hintergründe lassen sich kaum aufklären. Allerdings muß in jeder Schlacht mit Fehlleistungen und Koordinationsproblemen gerechnet werden. Zudem kann in einem Bürgerkrieg jede Eigenwilligkeit eines Unterführers rasch mißdeutet werden.

65 Cass. Dio 71, 29, $2 \mathrm{f}$.

66 HA Sev. 13, 1-9; vgl. G. Alföldy, Eine Proskriptionsliste in der Historia Augusta, in: ders., Krise (wie Anm. 13), 164-178 (Erstveröffentlichung 1968, hier mit Nachträgen).

67 Severus bestand auch gegenüber dem Senat darauf, als divi Commodi frater zu gelten, und ließ Commodus divinisieren: Cass. Dio 75, 7, 4. Manche Senatoren mokierten sich darüber, aber geholfen hat es nichts: Cass. Dio 76, 9, 3 (Pollenius Auspex, siehe PIR ${ }^{2}$ P 537). Klare Belege für diesen Titel gibt es erst ab 197: AE 1983, 872; CIL VIII 6994 = ILAlg. 
zwischen Caesar und Augustus konstruierte. Damit sollte wohl die 196 getroffene Nachfolgeregelung bekräftigt werden, ohne den Augustus-Titel an einen Sieg im Bürgerkrieg zu knüpfen.

Bereits im Sommer des Jahres 197 brach Severus mit seiner Familie erneut in den Orient auf und setzte den Krieg gegen die Parther fort. ${ }^{69}$ Vor der Öffentlichkeit wollte er sich wohl weniger als Mann des Bürgerkriegs, sondern als Sieger über die gemeinsamen äußere Feinde präsentieren.

In militärischer Hinsicht ist dies auch gelungen. Im Januar 198 wurde die parthische Hauptstadt Ktesiphon erobert. Unmittelbar darauf nahm Severus den Titel Parthicus maximus an: Erst damit war aus seiner Sicht der Krieg beendet. Gleichzeitig wurde sein Sohn Caracalla zum Augustus und sein anderer Sohn Geta zum Caesar erhoben. ${ }^{70}$ Die Nachfolgeregelung zugunsten der eigenen Familie wurde also dezidiert mit dem Parthersieg verbunden.

Die hier begründete Samtherrschaft folgte dem Modell derjenigen von Marc Aurel und Commodus. Auch wenn sie formal der Herrschaftsorganisation ähnelte, die Clodius Albinus gefordert hatte, so unterschied sie sich inhaltlich grundlegend davon: Severus blieb der eigentliche Herrscher, so wie es Marc Aurel gewesen war.

\section{Ausblick}

Septimius Severus war kein Revolutionär, nicht einmal ein großer Reformer. Seine Gesetzgebung und seine sonstigen Taten zeigen eher eine sozialkonservative Grundhaltung. Seinen Talenten und seinem Naturell nach war er soweit man das überhaupt sagen kann - kein Militär, sondern eher ein Jurist. Aber seine Herkunft und sein Weg zur Macht hatten dazu geführt, daß er sich vor allem auf seine Soldaten stützen mußte. Dabei ist es geblieben. Noch

2, 559; CIL VIII $5700=$ ILAlg 2, 567; P. IFAO 12; RIC IV 1 Caracalla Nr. 6. Ein terminus ante quem - der 4. oder 7. Mai 197 - ergibt sich aus CIL XIII 1754, vgl. J. Fitz, When did Caracalla become imperator destinatus?, Alba Regia 8/9, 1968, 285f. In der wohl unmittelbar nach der Schlacht von Lyon gesetzten Inschrift CIL XIII 6800 fehlt der Titel noch. Fitz (ebd.) erwägt, die Ernennung könne zu Caracallas Geburtstag am 4. April erfolgt sein. Das ist möglich, aber nicht beweisbar. - HA Sev. 14, 3: Caesarem dein Bassianum Antoninum a senatu appellari fecit decretis imperatoriis insignibus bezieht sich offenkundig auf die Erhebung zum imperator destinatus. - Zu einem möglicherweise ebenfalls damit zu verbindenden Kaiserbrief aus Aizanoi siehe unten Anhang 3.

69 Die Parther hatten während des Bürgerkriegs Mesopotamien besetzt und Nisibis belagert, das aber gehalten werden konnte: Cass. Dio 75, 9, 1.

70 HA Sev. 16, 3-5; HA Geta 5, 3, vgl. P. Dura 54. 
auf dem Totenbett soll er seinen Söhnen geraten haben: „Seid einig, bereichert die Soldaten und verachtet alles übrige."71 Septimius Severus ist damit zum ersten der Soldatenkaiser geworden. Er hat Männern von der Art eines Maximinus Thrax und eines Aurelian den Weg bereitet, obwohl er sie vermutlich verachtet hätte.

War dies unausweichlich? Das römische Kaisertum konnte verschieden aufgefaßt und ausgestaltet werden. Und gerade weil dem so war und die jeweils geltende Form erst im politischen Prozeß gefunden werden mußte, ist es zur Schlacht von Lyon gekommen. So muß es offen bleiben, ob die Geschichte denselben Verlauf genommen hätte, wenn Severus in dieser Schlacht gefallen wäre und Clodius Albinus das Kaisertum erobert hätte. Gewiß hätte auch Albinus seinen Soldaten Dank abstatten müssen. Aber er hätte z. B. zu einem weit besseren Verhältnis mit dem Senat finden können. Wie er seine Chancen genutzt hätte, können wir aber nicht wissen.

\section{Anhang 1: Iulia Domna mater castrorum}

Die moderne Forschung scheint sich einig zu sein, daß Julia Domna den prestigeträchtigen Titel mater castrorum am 14. April 195 erhielt. ${ }^{72}$ Das Datum ist freilich nicht überliefert, sondern wird durch eine Kombination mehrerer Zeugnisse erschloßen. ${ }^{73}$ Bei genauerer Prüfung erweist sich aber eines der herangezogenen Testimonien als nicht tragfähig. Gesichert ist das Tagesdatum, der 14. April: Dieser Tag wurde später in Ägypten als Jahresfest begangen. ${ }^{74}$ Das Jahr glaubt man hingegen einem Zeugnis aus Nordafrika entnehmen zu können: der Inschrift vom Architrav des Saturn-Tempels der Stadt Thugga. ${ }^{75}$ Zwar ist der Inschriftenträger in viele Stücke zerbrochen,

71 Cass. Dio $76,15,2$.

72 So z. B. PIR ${ }^{2}$ I 663; Kienast, Kaisertabelle (wie Anm. 34), 167; E. Kettenhofen, Die syrischen Augustae in der historischen Überlieferung. Ein Beitrag zum Problem der Orientalisierung (Antiquitas III 24), Bonn 1979, 80 mit 230 Anm. 42.

73 Die Münzen sind in diesem Fall unergiebig: RIC IV 1 Sev. 563a/b; 567; 568-569; 648A; $650 ; 860 ; 880 ; 884$ sind nicht datiert. In Alexandria wird lulia Domna erst ab dem Jahr 8 des Severus $(=199 / 200)$ als mater castrorum tituliert. Ebensowenig helfen die Provinzialmünzen aus dem Reichsosten weiter.

74 BGU 362, Sp. 11, Z. 15-17 (Abrechnung eines Tempels in Arsinoe): 10 ' sc. Pharmouthi

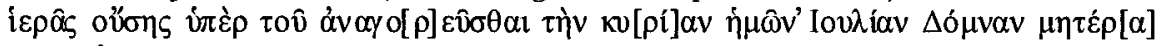

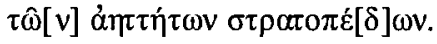

75 CIL VIII $26498=$ M. Khanoussi/L. Maurin, Dougga, Fragments d'histoire. Choix d'inscriptions latins éditées, traduites et commentées (I ${ }^{\text {er }}$ - IVe siècles), Bordeaux - Tunis, 
doch ist der Text lesbar, wenn auch an etlichen Stellen beschädigt. Aus der Kaisertitulatur des Septimius Severus (genauer: tri[b. pote]st. III cos. II in Fr. 6a/6b) ergibt sich eine zweifelsfreie Datierung in die Zeit zwischen dem 10. 12. 194 und dem 9. 12. 195. Bestätigt wird sie durch die Nennung des Clodius Albinus als Caesar, die später eradiert wurde. Auch Iulia Domna wird erwähnt (Fr. 8). Angeblich steht im unmittelbar anschließenden Fr. 9: [Aug(ustae) matris castr]orum..$^{76}$ Diese Lesung stammt von L. Poinssot ${ }^{77}$ und wurde von allen späteren Editoren übernommen. Der Erstherausgeber L. Carton hatte zu dem Fragment jedoch lapidar bemerkt: ,illisible ".78 Ebenso notierte der letzte Bearbeiter, $\mathrm{Z}$. Ben Abdallah: la surface épigraphe est complètement illisible depuis sa découverte; on ne distingue que la dermière lettre. ${ }^{79}$

Poinssot kann also wohl kaum alle vier angeblich erhaltenen Buchstaben gesehen haben, die dann zwingend zu [castr]orum zu ergänzen wären. Allem Anschein nach hat er nur konjiziert - zumal der Titel in späteren Inschriften überaus häufig vorkommt. Als Erstbeleg scheidet die Inschrift damit aus. ${ }^{80}$

Die frühesten eindeutigen Zeugnisse für den Titel mater castrorum stammen aus dem Jahr 196 und lassen sich mit Zeugnissen verbinden, in denen Caracalla bereits den Caesar-Titel führt. ${ }^{81}$ Stünde Iulia Domnas Titel tatsächlich bereits in der Inschrift aus Thugga, müßte man sich darüber wundern, daß sie so lange das einzige Zeugnis geblieben ist. So bleibt bei der gegenwärtigen Zeugnislage nur ein Schluß: Iulia Domna wurde erst am 14. April 196 zur mater castrorum ernannt. ${ }^{82}$

2000, Nr. 38.

76 Iulia Domna steht am Ende der kaiserlichen Personen; in Fr. 10 folgt: opus templi Saturni etc.

77 Siehe den app. crit. von CIL VIII 26498

78 Ebd.

79 In: Khanoussi/Maurin, Dougga (wie Anm. 75), Nr. 38. Trotzdem wird hier im Inschriftentext die angebliche Lesung Poinssots wiederholt.

80 Was in Fr. 9 wirklich stand, läßt sich derzeit nicht ergründen. Es muß sich nicht zwingend um einen Titel der Kaiserin gehandelt haben. Der Text könnte sich auch bereits auf den in Fr. 10 erwähnten Tempelbau beziehen.

81 CIL XII 4345 stammt von der Basis einer Statue, die Iulia Domna gewidmet war. Caracalla wird dort bereits als M. Aurelius Antoninus Caesar erwähnt; die Datierung auf 196 ergibt sich aus dem Titel des Septimius Severus (Arabicus Adiabenicus, tr. p. IIII, imp. VIII). - In IAM 2, 387 = ILAfr 613 (AE 1916, 89) aus Volubilis wird Caracalla ebenfalls als M. Aurelius Antoninus Caesar genannt; die Datierung ergibt sich wiederum aus dem Titel des Severus. - CIL XIV 120 (aus Ostia) ist selbst nicht datiert, doch wurde das Monument zusammen mit der Basis einer Statue für Caracalla alias M. Aurelius Antoninus Caesar gefunden, die fest auf 196 datiert ist (CIL XIV 121). - Siehe auch PIR² I 663.

82 Dem steht nicht entgegen, daß gelegentlich auch nach diesem Datum der Titel noch 


\section{Anhang 2: Das Datum der Caesar-Erhebung Caracallas}

Während früher angenommen wurde, Caracalla habe erst seit 196 den Caesar-Titel geführt, ${ }^{83}$ wird in der modernen Literatur vielfach die Meinung vertreten, er sei bereits im Jahr 195 in diesen Rang erhoben worden. ${ }^{84}$ Angeführt werden Konstitutionen, die im „Codex Iustinianus“ überliefert sind, ein Brief des Severus an die Bürger von Aizanoi und vor allem eine Inschrift aus Ulcisia castra (heute Szentendre).

Die Zeugnisse aus dem „Codex Iustinianus" 85 scheiden allerdings aus. Denn wie ein Blick in den Index lehrt, sind dort 66 Konstitutionen des Septimius Severus aus der Zeit von 193-197 überliefert, aber nur bei dreien wird Septimius Severus als alleiniger Augustus genannt, während Caracalla unerwähnt bleibt. ${ }^{86}$ In allen anderen Fällen haben die spätantiken Redaktoren regelmäßig und mechanisch den Namen Caracallas als Augustus ergänzt, also anachronistisch die spätere Normalform hergestellt. Der inschriftlich überlieferte Kaiserbrief aus Aizanoi ist seit langem umstritten - gerade was die Datierung betrifft (siehe auch Anhang 3). Von zentraler Bedeutung ist daher die Inschrift aus Ulcisia castra im heutigen Ungarn. ${ }^{87}$

Diese wurde von S. Soproni an Hand der Titulatur des Septimius Severus auf 195 datiert. 88 Der Text lautet:

fehlt, so z.B. in AE 1971, 28 aus Rom, einer Weihung für die Kaiserfamilie vom 29. 6. 196.

83 Siehe zum Beispiel RIC IV 1 S. 54; vgl. ferner das Referat der älteren Forschung bei D. Magie, Roman Rule in Asia Minor to the End of the Third Century After Christ, Princeton N.J. 1950, $1541 \mathrm{f}$.

84 Birley, Septimius Severus (wie Anm. 2), 117-120. - Kienast, Kaisertabelle (wie Anm. 34), 162 bleibt unentschieden. - Sehr viel Material zur Entwicklung der Titulatur findet sich bei A. Mastino, Le titolature di Caracalla e Geta attraverso le iscrizioni (Indici), Bologna 1981.

85 Magie, Asia Minor (wie Anm. 83), $1541 \mathrm{f}$. verwies auf CJ 9, 41, 1, eine Konstitution vom 1. 1. 196, als deren Urheber impp. Severus et Antoninus $A A$. bezeichnet werden. Ihm folgen unter anderem S. Soproni, Die Caesarwürde Caracallas und die syrische Kohorte von Szentendre, Alba Regia 18, 1980, 39-51 und J. H. Oliver, Greek Constitutions of Early Roman Emperors from Inscriptions and Papyry, Philadelphia, 1989, 433. Allerdings hätte auffallen sollen, daß Caracalla damals noch nicht Augustus war, die Kaisertitulatur also in jedem Fall anachronistisch ist. - Hasebroek, Septimius Severus (wie Anm. 2), 87 verweist auf die Konstitution CJ 4, 9, 1 [recte 4, 19, 1] vom 30. 6. 196. Hierzu gilt das Gesagte analog.

86 CJ $2,47,1 ; 4,14,1 ; 2,3,1$.

87 RIU III $840=$ AE 1982,817 .

88 Soproni, Caesarwürde (wie Anm. 85). 


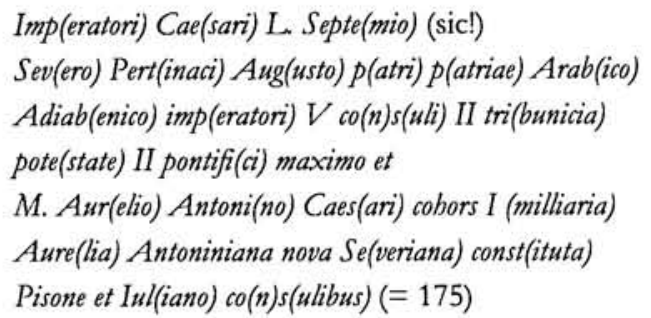

In der vorletzten Zeile stand ursprünglich Aure(lia) Antonina S(urorum). Die Einheit ist also offensichtlich bald nach der Errichtung des Monuments umbenannt und die Inschrift nachträglich angepaßt worden. ${ }^{89} \mathrm{Im}$ übrigen macht diese nicht den Eindruck, als sei ein Könner am Werk gewesen. Der Text weist nicht nur zahlreiche Ligaturen auf, sondern auch viele ungewöhnliche Abkürzungen und einen erstaunlichen Fehler im Namen des Kaisers. Die Titulatur des Severus, von der die Datierung abhängt, ist in sich inkonsistent. Denn seine hier erwähnte zweite tribunicia potestas umfaßt die Zeit von Dezember 193 bis Dezember 194. Die fünfte Imperator-Akklamation nahm Severus jedoch erst in der ersten Hälfte von 195 an, ${ }^{90}$ auf die dann rasch imp. VI und imp. VII folgten. Auch den Titel Arabicus Adiabenicus trug Septimius Severus erst ab 195. Soproni glaubte, daß tribunicia potestate II einfach zu tribunicia potestate III zu verbessern sei. Das ergäbe zwar eine konsistente Nomenklatur des Kaisers (und eine klare Datierung auf 195), aber bei der ohnehin fehlerhaften Inschrift bliebe zu fragen, ob nicht auch anderes falsch sein könnte und z. B. auch bei der - von Soproni akzeptierten - Angabe der Imperator-Akklamationen ein paar Hasten vergessen worden seien. In jedem Fall steht die angeblich früheste Bezeugung Caracallas als Caesar auf Konjektur, und als einziges Zeugnis reicht sie kaum aus. ${ }^{91}$

$89 \mathrm{Da}$ dies im Jahr 212 geschehen sei, wie im Kommentar zu RIU III 840 behauptet wird, ist ganz unbewiesen.

90 Auch an den Münzen läßt sich ersehen, daß es die Kombination von tr. pot. II mit imp. $V$ nicht gab.

91 Soproni, Caesarwürde (wie Anm. 85), 40 meinte, die Inschrift sei aus Anlaß des zwanzigjährigen Bestehens der Einheit gesetzt worden, was ebenfalls auf 195 führen würde. Allerdings wurden solche Jubiläen in der römischen Armee gar nicht gefeiert. Auch die Vicennalien der Kaiser können nicht als Parallele herangezogen werden, da diese sich aus vota decennalia begründeten. Solche vota gab es für Truppenverbände nicht. Der sehr ungewöhnliche Hinweis auf das Gründungsdatum diente wohl eher dazu, diskret zu verdeutlichen, daß die Kohorte ihren Beinamen nicht nach dem neuen Caesar M. Aurelius Antoninus (d. h. Caracalla) führte, sondern nach dem allseits verehrten Kaiser Marc Aurel. 
Eindeutige inschriftliche Zeugnisse sowie eindeutig datierte Papyri gibt es erst ab dem Jahr 196. ${ }^{92}$ Die Untertanen werden kaum lange gezögert haben, dem neuen Caesar ihre Reverenz zu erweisen. Wollte man die CaesarErhebung - unter Berufung auf die Inschrift aus Ulcisia castra - auf 195 datieren, müßte man einen zeitlichen Hiat erklären.

In der Münzprägung zeigt sich ein ähnlicher Befund: Es gibt keine Anspielung auf die Caesar-Erhebung, die auf 195 datiert werden müßte. Den frühesten Hinweis bietet wohl der (undatierte) Typus RIC IV 1 Caracalla 3-4 (Aureus/Denar), der auf seiner Vorderseite die Legende M. Aur. Antonius Caes. trägt und auf der Rückseite Severi Aug. Pii fil. Möglicherweise ist er mit dem Münztypus RIC IV 1 Severus 72 (Aureus) zu verbinden, der auf der Vorderseite L. Sept. Sev. Pert. Aug. imp. VII und auf der Rückseite Severi Aug. Pii fil. bietet. Denn die Parole Severi Aug(usti) Pii fil(ius) spielt sonst keine Rolle. Die siebente Imperator-Akklamation des Severus findet man auf anderen Münzen sowohl zusammen mit tr. pot. III (Dezember 194 - Dezember 195) als auch mit tr. pot. IV (Dezember 195 - Dezember 196). ${ }^{93}$ Es ist also gut möglich, daß beide Typen erst im Frühjahr 196 emittiert wurden.

Schließlich kollidiert das Datum 195 mit der literarischen Überlieferung. Denn in der „Historia Augusta“ wird berichtet, Caracalla sei in Viminacium (ca. $55 \mathrm{~km}$ östlich von Belgrad an der Donau gelegen) zum Caesar erhoben worden, und zwar auf der Durchreise. ${ }^{94}$ An der Glaubwürdigkeit der Notiz ist kaum zu zweifeln, und sie wird in der Forschung weithin akzeptiert. Es ist aber auszuschließen, daß sich Severus und Caracalla im Jahr 195 in Viminacium aufhielten. Wie ihr Itinerar zeigt, sind sie erst im Frühjahr 196 aus dem

92 Die früheste genau datierte Inschrift ist AE 1971, 28 vom 29. 6. 196. Siehe ferner IAM 2, 387 (Severus mit tr. p. IIII, imp. VIII), CIL XIV 114 und addenda ebd. S. 613, vgl. auch auch AE 1968, 8b = Denkm. Kaiserreiter 54 (vom 1. 1. 197) - Papyri: P. Ryl. 169. - Im Kommentar zu RIU III 840 wird angegeben, CIL X 3341 stamme aus dem Dezember 195. Jedoch ist die Inschrift durch tr. pot. IIII und imp. VIII des Severus datiert, stammt also aus der Zeit zwischen dem 10.12. 195 und dem 9. 12. 196. Ferner wird auf die Inschrift CIL III 14507 verwiesen: eine Weihung von Legionären, die [Cle]ment. et Prisco cos. - also 195 - entlassen worden sind. Die Inschrift ist jedoch stark beschädigt, und das Entlassungsdatum der Soldaten liefert nur einen terminus post quem.

93 Für letzteres siehe RIC IV 1 Severus 70-71A und 714-717, ferner die Inschrift CIL X 6437 (CIL XI 8 ist nur handschriftlich überliefert). - Keine Grundlage hat die Auffassung, Septimius Severus habe Ende 195 bereits seine achte Imperator-Akklamation angenommen, vgl. unten Anm. 101.

94 HA Sev. 10, 3: et cum iret contra Albinum, in itinere apud Viminacium filium sum maiorem Bassianum adposito Aurelii Antonini nomine Caesarem appellavit, ut fratrem suum Getam ab spe imperii, quam ille conceperat, summoveret. 
Orient nach dem Westen gereist, um gegen Clodius Albinus zu ziehen. ${ }^{95}$ Soproni nahm daher Zuflucht zur Hypothese, Caracalla sei zweimal zum Caesar erhoben worden, nämlich einmal 195 und einmal im Frühjahr 196 in Viminacium. ${ }^{96}$ Dies ist jedoch eine offensichtliche Notlösung, die sich durch nichts stützen läßt.

Man darf vielmehr festhalten, daß die Caesar-Erhebung aller Wahrscheinlichkeit nach im Frühjahr 196 stattfand. Caracalla wurde vor dieser Zeit auch nicht als ,M. Aurelius Antoninus' bezeichnet; jedenfalls gibt es dafür keinen Beleg (außer der Inschrift aus Ulcisia castra). ${ }^{97}$

\section{Anhang 3: Der Brief des Septimius Severus an die Stadt Aizanoi}

Schwierigkeiten bereitet seit langem die Datierung und Einordnung eines Briefs von Septimius Severus an die Stadt Aizanoi in der Provinz Asia, der durch eine - heute verlorene - griechische Inschrift bekannt ist. ${ }^{98}$ In dem Brief bedankt sich der Herrscher bei den Bürgern von Aizanoi für eine Gratulationsgesandtschaft. Deren Anlaß wird ebenso wortreich wie unspezifisch umschrieben: „Die Freude, die ihr wegen der Erfolge (oder: weil die Dinge richtig geordnet wurden) hegt und weil mein Sohn Marcus Aurelius Antoninus - mit gutem Glück! - zu den Hoffnungen auf die Herrschaft aufstieg und dem Vater beigeordnet wurde, habe ich aus euerem Beschluß ganz klar erkannt usw.".99

$\mathrm{Zu}$ datieren ist der Brief nur anhand der Kaisertitulatur des Severus. Er trägt den Siegerbeinamen Arabicus Adiabenicus und wird als Sohn Marc Aurels und Bruder des Commodus bezeichnet; ferner werden die dritte

95 Siehe die Zusammenstellung der Daten bei Halfmann, Kaiserreisen (wie Anm. 41), 217

96 Soproni, Caesarwürde (wie Anm. 85), 43.

97 Aus HA Sev. 10, 3-6 ergibt sich klar, daß die Umbenennung und die Caesarerhebung simultan erfolgten. - Bemerkenswerterweise wurde danach nur noch bei einer einzigen Erwähnung des neuen Caesar dessen altes Cognomen ,Bassianus' hinzugefügt: in einer Inschrift aus Tunesien, die auf 197 datiert ist (AE 1904, 75). Es handelt sich offenkundig um ein Versehen, weil die Inschriftensetzer noch nicht genau genug verstanden hatten, welche Namensform politisch gewollt war.

98 ILS $8805=$ Oliver, Constitutions (wie Anm. 85), Nr. 213. Der Text beruht auf Abschriften von A. de Laborde und Ph. Le Bas aus dem 19. Jahrhundert, die den Stein noch gesehen haben.

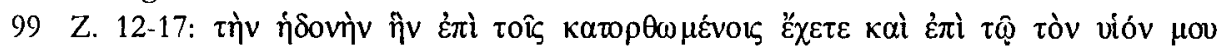

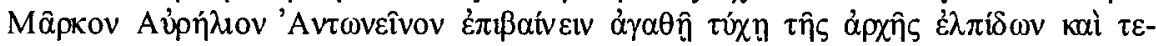

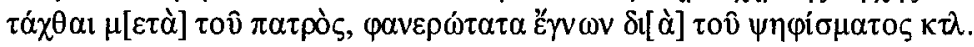


tribunizische Gewalt, die achte Imperator-Akklamation und der zweite

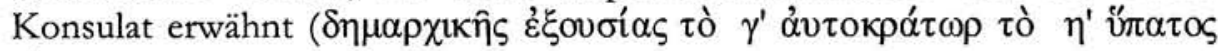
$\tau$ ò $\beta^{\prime}$ ). Die verschiedenen Elemente passen aber auch hier nicht zusammen. Die dritte tribunizische Gewalt würde auf die Zeit zwischen dem 10. 12. 194 und dem 9. 12. 195 führen; die achte imperator-Akklamation ist aber nur zusammen mit der vierten und fünften tribunizischen Gewalt belegt, was sich an der Reichsmünzprägung zuverlässig nachverfolgen läßt. ${ }^{100}$ Dies wäre die Zeit zwischen dem 10.12. 195 und dem 9. 12. 196 bzw. zwischen dem 10. 12. 196 und dem 9. 12. 197.

Etliche Forscher haben sich an die tribunicia potestas gehalten und den Brief auf 195 datiert. ${ }^{101}$ Träfe das Datum zu, müßte Caracalla in diesem Jahr zum Caesar erhoben worden sein, und die Bürger von Aizanoi hätten aus eben diesem Anlaß ihre Gratulationsgesandtschaft geschickt. ${ }^{102}$ Dem sind jedoch nicht nur die oben angeführten Gründe entgegenzuhalten. Auch die Inschrift aus Aizanoi ist wohl anders zu datieren. Bereits frühere Editoren hatten einen Schreib- oder Lesefehler in der Inschrift vermutet und die

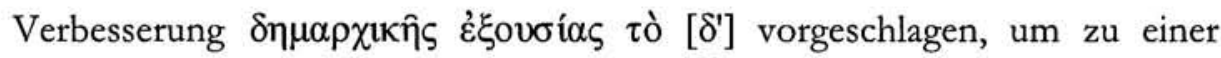
konsistenten Kaisertitulatur zu gelangen. ${ }^{103}$ Dies würde in die Zeit von Dezember 195 bis Dezember 196 führen.

Doch gibt es noch eine weitere, bislang kaum beachtete Lösungsmöglichkeit, auf die es hinzuweisen gilt: Paläographisch läge es am nächsten, an der fraglichen Stelle $\Gamma^{\mathfrak{c}} \mathrm{zu}, \mathrm{E}^{\mathrm{c}} \mathrm{zu}$ verbessern. Dann wäre von der fünften tribunizischen Gewalt die Rede gewesen, die in die Zeit vom 10.12. 196 bis

100 RIC IV 1 Severus Nr. 83; 90; 722; 724; 733 bzw. 87; 489; 726.

101 So Oliver, Constitutions (wie Anm. 85), S. 433 und Birley, Septimius Severus (wie Anm. 2), 119. Oliver (ebd.) übergeht das Problem der inkonsistenten Titulatur mit der Bemerkung: , ... the eighth imperial salutation cannot be dated much earlier than December (scil. 195)“. Doch gibt es sonst kein Zeugnis für imp. VIII aus der Zeit vor dem Wechsel von tr. pot. III zu tr. pot IV am 10. Dezember 195. Auch Birley (ebd.) gibt mit Bezug auf diese Inschrift an, Severus sei noch vor Ende $195 \mathrm{imp}$. VIII geworden. Den im Kaiserbrief erwähnten Erfolg identifiziert er (wie Oliver) mit der Einnahme der Stadt Byzantion. Diese ist aber ihrerseits schwer zu datieren: Byzantion soll der Belagerung durch die Truppen des Severus mehr als drei volle Jahre getrotzt haben (Cass. Dio 74, 12,1) und Severus soll vom Fall der Stadt erfahren haben, als er sich noch in Mesopotamien aufhielt (Cass. Dio 74, 14, 2). Jedoch kann die Belagerung frühestens im Sommer 193 begonnen haben, und Severus hat sich spätestens im Frühjahr 196 wieder auf den Rückweg aus dem Orient gemacht.

102 Ebd.

103 Vgl. den Kommentar bei Oliver, Constitutions (wie Anm. 85), Nr. 213 und das Referat bei Magie, Asia Minor (wie Anm. 83), 1542. 
9. 12. 197 gehörte. Diese ist zusammen mit der achten ImperatorAkklamation gut belegt. Mit dem im Brief erwähnte Erfolg müßte demnach der Sieg bei Lyon und mit Caracallas Rangerhöhung seine Ernennung zum imperator destinatus gemeint sein. Das Dokument müßte also in die Zeit bald nach beiden Ereignissen gehören. Allerdings glaubt man zu wissen, daß Septimius Severus bereits anläßlich der Schlacht bei Lyon seine neunte Imperator-Akklamation angenommen hat. ${ }^{104}$ Demnach wäre bei der hier

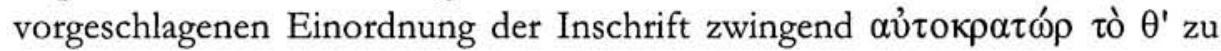
erwarten.

Aber genau besehen ist dieser Zeitansatz der neunten Akklamation seinerseits nicht gesichert, sondern beruht lediglich auf einer Vermutung. Denn eigentlich weiß man nur, daß tr. pot. $V$ (aus der Zeit vom 10.12. 196 bis 9. 12. 197) zusammen mit imp. VIII, imp. IX und imp. $X$ belegt sind, ferner daß imp. IX auf Münzen zusammen mit der Parole profectio Augusti erscheint, ${ }^{105}$ was sich offensichtlich auf den Aufbruch in den zweiten Partherkrieg bezog, und schließlich daß imp. $X$ auf Münzen mit Vict(oriae) Partbicae verbunden wurde, ${ }^{106}$ also offenkundig bereits in die Zeit des neuen Partherkrieges gehörte. Spätestens im Spätherbst $197 \mathrm{muß}$ also imp. X erreicht gewesen sein, und demnach wird der Kaiser vor dem Spätsommer die neunte Akklamation angenommen haben.

Die zehnte Akklamation ist ohne weiteres mit den Kampfhandlungen im zweiten Partherkrieg zu verbinden. Die vorherrschende Hypothese verbindet die neunte Akklamation nun einfach mit dem uns bekannten großen Erfolg in dem dafür in Frage kommenden Zeitraum - mit der Schlacht von Lyon. Stillschwiegend wird dabei unterstellt, daß Septimius Severus sich nicht gescheut habe, den Bürgerkrieg, das große Blutbad unter Römern, offen wie einen Sieg über äußere Feinde zu feiern, ${ }^{107}$ wiewohl es darüber keine Nachrichten gibt. Ob sich Severus tatsächlich dazu hinreißen ließ, der Öffentlichkeit gegenüber einen derartigen Zynismus an den Tag zu legen, kann man aber bezweifeln, zumal wir wissen, daß er selbst sich als untadeligen Sieger darzustellen suchte. ${ }^{108}$

104 Siehe z. B. Kienast, Kaisertabelle (wie Anm. 34), 157; RIC IV S. 54.

105 RIC IV 1 Severus Nr. 106; 740A.

106 RIC IV 1 Severus Nr. 121; vgl. Nr. 120: Vict(oria) Aug(ustorum).

107 Die senatorische Geschichtsschreibung leistet solchen Vermutungen Vorschub, bemüht sie sich doch sichtlich, Septimius Severus als grausamen Sieger hinzustellen, siehe Cass. Dio 75, 7, 3-4 (der hier erklärtermaßen - und charakteristischerweise - von Severus' eigener Version abweicht), vgl. Herod. 3, 7, 7; HA Sev. 11, 5-9; HA Clod. Alb. 9, 3-7.

108 Cass. Dio 75, 7, 3-4 (vgl. die vorausgehende Anm.). 
Zudem gibt es ein statistisches Problem: Nach der vorherrschenden Meinung hätte Septimius Severus die Kombination der Titel tr. pot. $V$ und imp. VIII nur in der Zeit vom 10.12. 196 bis zum 19.2. 197 getragen, also wenig länger als zwei Monate, die Kombination der Titel tr. pot. $V$ und imp. IX hingegen mindestens ein halbes Jahr. Doch gibt es recht viele Inschriften und etliche Münztypen mit tr. pot. V und imp. VIII. ${ }^{109}$ Diejenigen mit tr. pot. $V$ und imp. IX sind - anders als man erwarten sollte - nicht wesentlich zahlreicher, sondern eher weniger. ${ }^{110}$

Schließlich scheint eine in diesem Zusammenhang bedeutsame lateinische Inschrift übersehen worden zu sein: Die Bürger der Gemeinde Sigus in Nordafrika - $35 \mathrm{~km}$ südöstlich von Cirta gelegen - haben für Caracalla ein Monument errichtet, in dessen Inschrift er als M. Aurelius Antoninus Caes(ar) imp(erator) destinatus angesprochen wird. ${ }^{111}$ Dem Namen wird eine ausführliche Filiation beigefügt, in der sein Vater Septimius Severus mit den Titeln [tr]ib. pot. V, imp. VIII, cos. [II, pr]ocos. erscheint. Er trägt also die gleiche Titulatur, wie sie hier für die Inschrift aus Aizanoi postuliert wurde, und diese gehört in die Zeit, als Caracalla bereits imperator destinatus war.

Sofern dem Steinmetzen kein Fehler unterlaufen ist (worauf nichts hindeutet), kann sich die neunte Imperator-Akklamation des Severus also nicht auf die Schlacht bei Lyon beziehen. Vielmehr kann sie der Kaiser erst einige Zeit danach angenommen haben, ungefähr im späten Frühjahr oder Sommer 197. Der Anlaß bleibt unbekannt; es könnte sich zum Beispiel um einen siegreich bestandenen Zwischenfall an der Partherfront gehandelt haben. ${ }^{112}$

Der hier unterbreitete Vorschlag, den Kaiserbrief aus Aizanoi ins Jahr $197 \mathrm{zu}$ datieren, steht also im Einklang mit der Zeugnislage. Auch die unpräzise Sprache des Dokuments ließe sich aus den Zeitumständen gut erklären: Es ging um den Sieg im Bürgerkrieg, den Severus angeblich nicht gewollt und stets bedauert hat. Deshalb wurde es vermieden, von einem

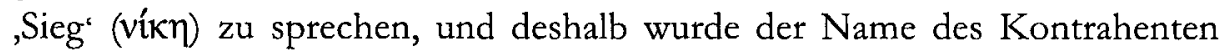
totgeschwiegen. Und was Caracallas neuer, ad hoc erfundener Rang eigentlich bedeuten sollte, konnte man nur mit unscharfen Wendungen umschrei-

109 Inschriften: CIL VI 40600; CIL VIII $5700=$ ILAlg 2, 567; CIL X $6079=$ ILS 420; AE 1969/70, 697; AE 1981, 38; AE 1983, 872; vgl. AE 1975, 870 (ergänzt); Münzen: RIC IV 1 Severus $87 ; 489 ; 726$.

110 Inschriften: CIL VIII 26255 = ILS 9401; VIII 26256, Münzen: RIC IV 1 Severus 101; 738.

111 CIL VIII 5700 (vgl. VIII 19113) = ILAlg 2, 567. Name und Titel stehen im Dativ.

112 In Frage käme z. B. die erfolgreiche Abwehr der parthischen Belagerung von Nisibis, Cass. Dio $75,9,1$. 
ben. Möglicherweise gab es dafür auch noch keinen griechischen Terminus. ${ }^{113} \mathrm{Ob}$ im Text wirklich,$\Gamma^{`}$ und nicht,$E^{`}$ stand, ließe sich freilich abschließend nur am Stein selbst klären. Dieser ist aber bislang nicht wieder aufgefunden worden. ${ }^{114}$

113 Anderswo findet man die Formulierung $\alpha$ (aus Messene) - eine Lehnübersetzung des lateinischen imperator destinatus.

114 L. Schumacher, Die politische Stellung des Clodius Albinus (193-197 n. Chr.), JRGZ 50, 2003 [2004], 355-369 ist erst nach Manuskriptabschluß erschienen, sodaß hier nicht mehr näher darauf eingegangen werden kann. Die Überlegungen Schumachers berühren sich in etlichen Punkten mit denen, die hier vorgetragen wurden. Das betrifft auch Kernfragen der Chronologie (so die Bewertung von RIU III 840 und die Datierung der CaesarErhebung Caracallas auf 196). Zu diskutieren bliebe aber, ob sich die Rechtsstellung des Albinus als Caesar so genau bestimmen läßt, wie Schumacher vermutet, und ob Septimius Severus seinen Caesar Clodius Albinus tatsächlich bereits 195 unmißverständlich zum Bürgerkrieg provoziert hat. 


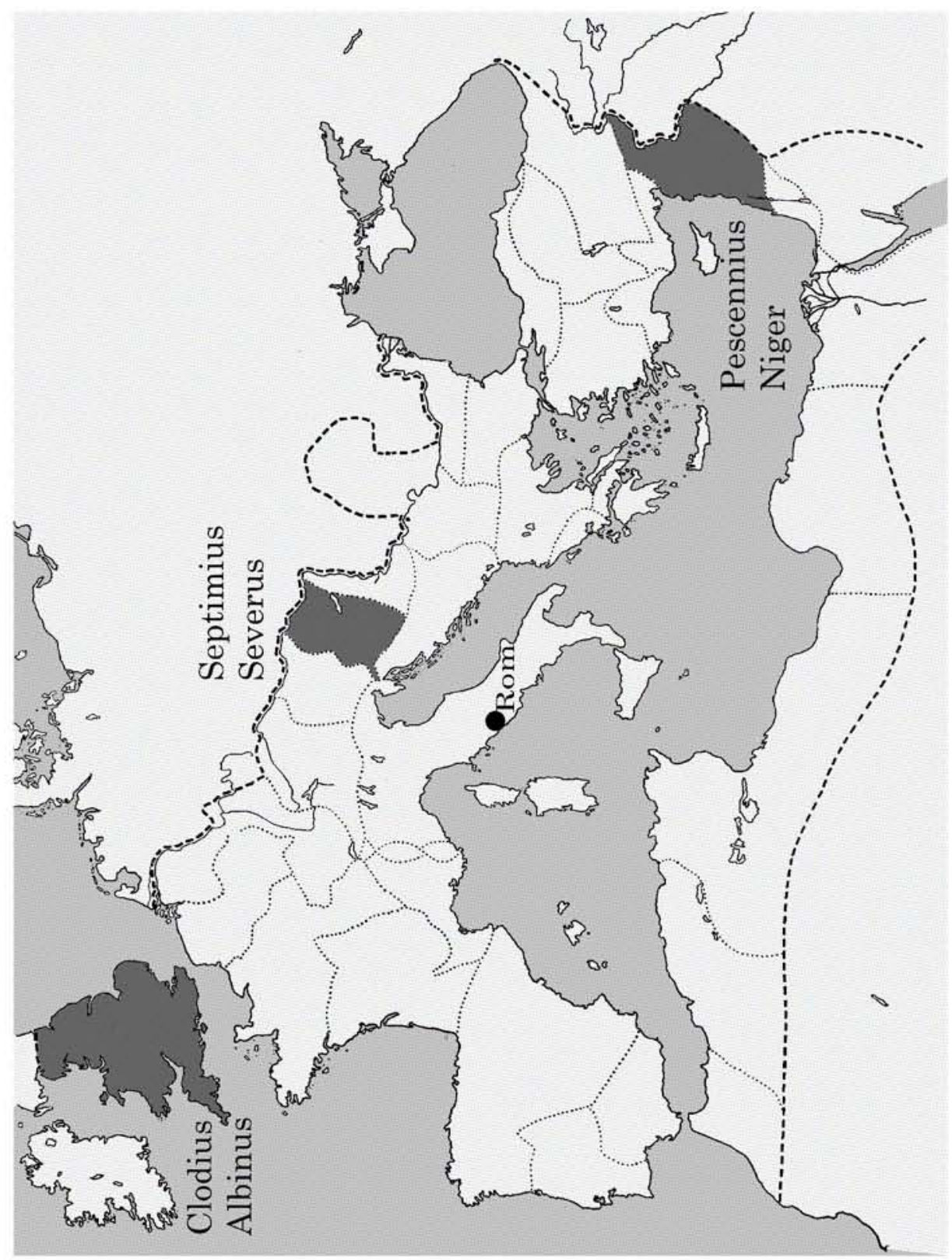

Abbildung 1: Die Prätendenten von 193 n. Chr. 


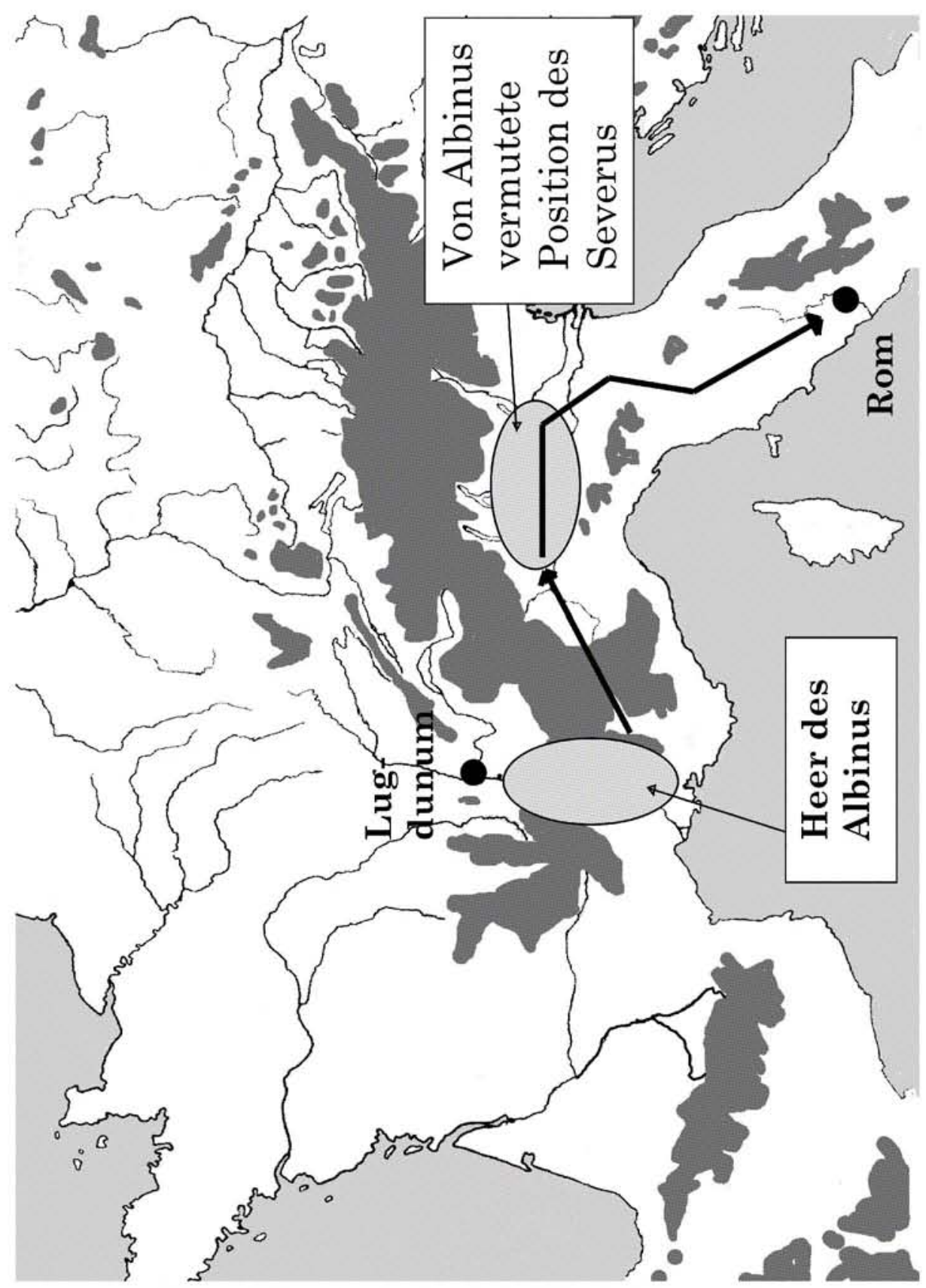

Abbildung 2: Der Kriegsplan des Clodius Albinus im Jahre 197 n. Chr. 


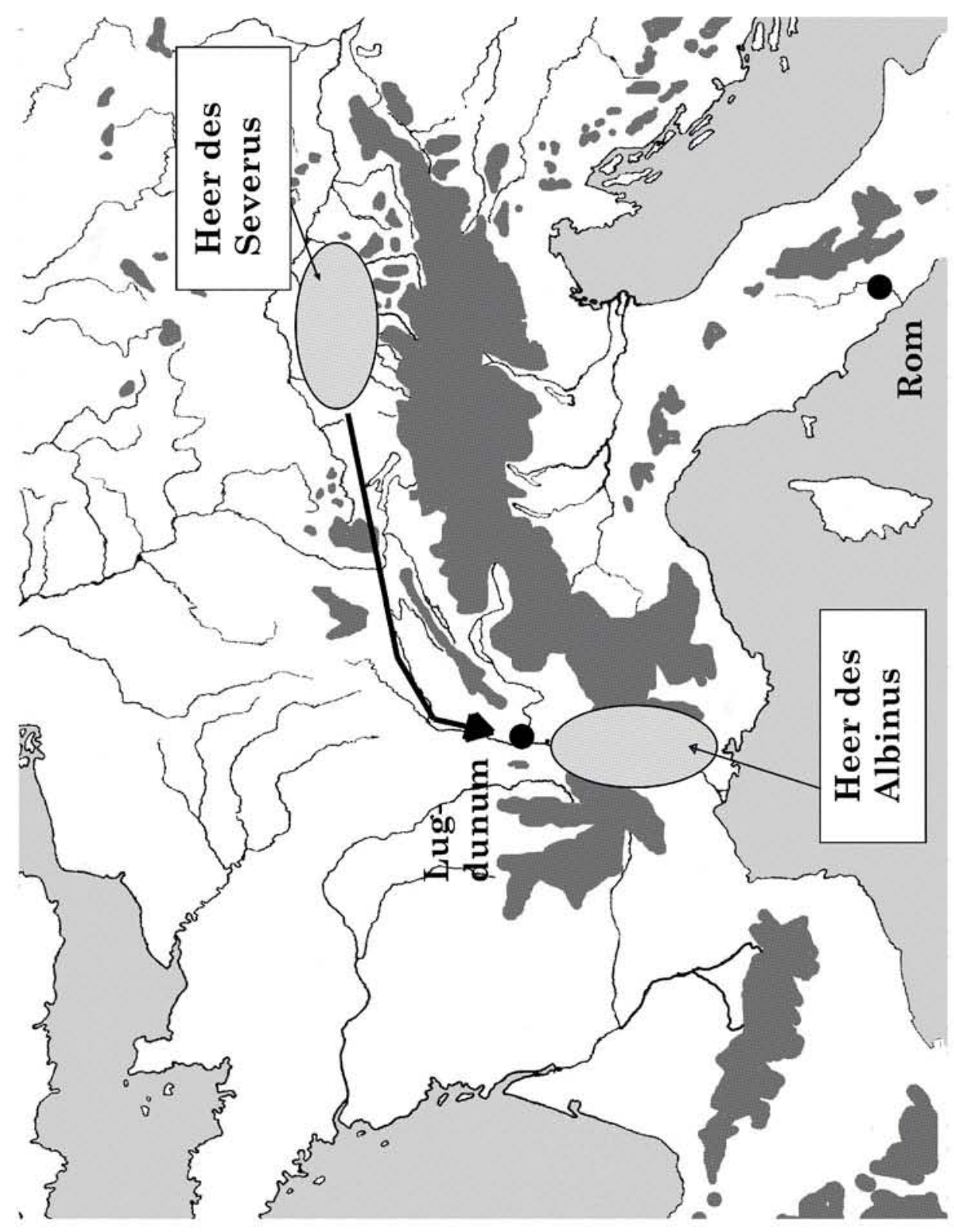

Abbildung 3: Der Kriegsverlauf des Jahres 197 n. Chr. 
